\title{
ORIGINAL RESEARCHARTICLE \\ Unpacking Business Model Innovation Through an Attention-Based View
}

\author{
Alexis Laszczuk ${ }^{*}$ and Julie C. Mayer ${ }^{2}$ \\ 'ESSCA School of Management, Boulogne-Billancourt, France; ${ }^{2}$ Université Paris-Dauphine, UMR CNRS 7088 - PSL, \\ Management et Organisation (M\&O), Paris, France
}

\begin{abstract}
Attention is considered as a critical driver for business model (BM) innovation in established firms, where existing activities already absorb internal actors' time and effort. Although previous studies acknowledge the role of attention to detect opportunities or to generate new ideas, we still need to understand how actors deal with attentional tensions inherent in the development of a new additive BM. This article addresses this issue by adopting an attention-based view of BM innovation, that is, by examining the forms of attention involved in the process of developing a new BM.Through a longitudinal study in a small consulting company, we unfold an incremental and ongoing process of new BM development. Our findings identify three attentional stages triggered by specific mechanisms that drive BM innovation, from detecting new ideas to their implementation. The attentional perspective we use in this study revises the role of a prevailing BM in the emergence of new business logics in established firms. While previous studies consider it as an impediment for BM innovation, we reveal that actors can develop new BMs by navigating between differentiation and consistency with the prevailing BM.
\end{abstract}

Keywords: Business model innovation; Attention-based view; Strategy; Qualitative study; Observation

Received: 18 December 2017; Accepted: 20 December 2019; Published: 30 March 2020

1 a fast-changing environment, business model innovation (BMI), that is, the process of organizing businesses in a new way (Casadesus-Masanell \& Zhu, 20I3), is considered to be a critical source of sustained value creation and sustainable performance (Mangematin, Ravarini, \& Sharkey Scott, 2017). While new products or services can be copied, the ability to adopt new business logics provides a durable vector of distinction (Giesen, Berman, Bell, \& Blitz, 2007). The skyrocket growth of iconic Internet firms, such as Amazon or Google, has raised significant interest for their ability to constantly develop new business models (BMs). However, public institutions and consulting companies continue to point out the organizational challenges of achieving BMI (European Commission, 20 I 4; IBM Corporation, 2008; Lindgardt, Reeves, Stalk, \& Deimler, 2009).

In response, a growing research stream examines the organizational drivers and antecedents of BMI (Aversa, Haefliger, Rossi, \& Baden-Fuller, 2015; Berends, Smits, Reymen, \& Podoynitsyna, 2016; Foss \& Saebi, 2017). The existing studies shed light on the various contexts in which BMI occurs, not only for start-up creation (Bojovic, Genet, \& Sabatier, 2018) but also for the development of new activities in established firms (Mezger, 2014). Acknowledged as particularly complex (Massa \& Tucci, 20I4), BMI in an established firm constitutes a recent agenda of research (Demil, Lecocq, Ricart, \& Zott, 2015).

Managers of established firms conduct BMI according to various strategies (Santos, Spector, \& Van Der Heyden, 2015): they replace the incumbent BM (Moingeon \& Lehmann-Ortega, 20I0) or develop additional activities inside (Winterhalter, Weiblen, Wecht, \& Gassmann, 2017) or outside (Lehoux, Daudelin, Williams-Jones, Denis, \& Longo, 2014) the company. While the scholarship acknowledges that BMI should be led by an internal dedicated team (Khanagh, Volberda, \& Oshri, 20I4), the process through which internal actors (also in charge of current activities) develop a new additive BM remains largely unexplored. In particular, previous studies have suggested that internal actors' ability to innovate is driven by their limited attention, which is stressed as an overlooked core driver of BMI (Dahlander \& O'Mahony, 20 16). On the one hand, attention allows actors to detect opportunities or to focus on new idea incubation (Li, Maggitti, Smith, Tesluk, \& Katila, 20।3).

*Corresponding author: Alexis Laszczuk, Email: alexis.laszczuk@essca.fr 
On the other hand, attention can also interfere with innovation by enclosing actors in time-and-effort-consuming activities driven by the prevailing BMs.

To determine how attention shapes BMI within incumbent firms, we draw on the attention-based view (ABV) (Ocasio, 1997). The ABV defines attention as the noticing, encoding, interpreting, and focusing of time and effort by organizational actors on a limited set of issues. The ABV relies on the idea that organizational and strategic change is driven by the allocation of actors' attention (Orvain, 20 I4; Shepherd, McMullen, \& Ocasio, 2017). Because attention is limited (Simon, 1947), internal actors constantly make arbitrages: they address a limited number of issues by allocating different forms of attention (Ocasio, 20l I), that is, by selecting issues (selective attention), by engaging managerial efforts (engaged attention), and by redistributing organizational resources (distributed attention).The ABV thus provides a useful lens to reveal innovative processes (Li et al., 2013). Accordingly, we address the following research question: how does internal actors' attention shape the development of a new additive BM in an established firm?

To answer this question, we conducted a longitudinal analysis of a new additive BM development by a BMI team (composed of internal actors) within a small consulting company over several years. Our findings captured an emergent and ongoing process of BMI driven by three attentional phases applied to several objects of attention. We revealed the mechanisms that trigger changes of attention forms and allow actors to select, develop, and concretize ideas that progressively feed the new BM.

This study provides several contributions. First, it extends the knowledge regarding BMI in incumbent firms (Arend, 20 I3; Demil et al., 2015) by spotlighting attention as a mechanism through which a new additive BM is developed while maintaining the prevailing BM (Velu \& Stiles, 20I3). It specifies the role of attention in the process of BMI (Foss \& Saebi, 2017) by clarifying how different forms of attention lead to the incremental construction of a new BM. Second, it provides empirical insights that refine the $A B V$ model by highlighting the triggers that allow shifts of attention over time (Ocasio, 20l I).

This article is structured as follows. First, we introduce our theoretical framework, which articulates the BMI and ABV literatures. Second, we expose our methodology. Then, we describe our findings and discuss the contributions of the study.

\section{Theoretical framework}

After introducing the concept of BM and BMI, we justify the need to further explore the role of attention in the BMI process. Then, we mobilize the ABV as a conceptual lens to enhance the understanding of BMI.

\section{Business model innovation}

The growing literature on BM in the fields of strategy and entrepreneurship since the late 1990s reflects the popularity of the concept (Demil et al., 2015; Maucuer \& Renaud, 2019) for both scholars and practitioners (Lecocq, Demil, \& Ventura, 2010). The flourishing literature on BM provides numerous definitions that are converging toward a consensus: BM refers to the logic of the firm for value creation, delivery, and capture (Baden-Fuller \& Morgan, 2010; Demil \& Lecocq, 2010; Teece, 2010; Zott \& Amit, 2010). Due to various ontological assumptions about BM (Massa, Tucci, \& Afuah, 2017), the literature provides a rich diversity of definitions. While most of them consider BM to be a descriptive output, the recent scholarship argues that it rather represents a collective device for business exploration, which brings progressively new activities into existence (Doganova \& Eyquem-Renault, 2009). Following the recent studies (Aversa et al., 20 I 5; Bojovic et al., 20 I 8), we adopt a process view of $\mathrm{BM}$ that allows to address decisive issues such as how a new BM is developed (Baden-Fuller \& Mangematin, 2015), leading to the study of BMI.

$\mathrm{BMI}$ refers to "the search for new logics of the firm and new ways to create and capture value for its stakeholders" (Casadesus-Masanell \& Zhu, 20I3, p. 464). In this view, BMI goes beyond product or service innovation and involves the reshaping of a firm's activities and operations (Bjorkdahl \& Holmén, 2013). BMI is an important aspect for competition and performance (Bjorkdahl, 2009; Casadesus-Masanell \& Ricart, 2010): consequently, it is considered by many practitioners and academics to be a source of competitive advantage (Chesbrough, 2010; Foss \& Saebi, 2015; Zott \& Amit, 2007). Thus, the academic literature invites further research to shed light on BMI drivers (Foss \& Saebi, 2017) to understand how actors develop a new BM (Baden-Fuller \& Mangematin, 2015; Demil \& Lecocq, 2015) or identify antecedents, leading to a BM adoption (Rumble \& Mangematin, 20 I5). Developing a new BM is known to be a challenging activity (Chesbrough, 2010), both for new ventures (Bojovic et al., 2018) and incumbent firms (Berends et al., 2016). Scholars invite for further research on the latter (Arend, 20I3; Demil et al., 20I5) as BMI is considered to be more difficult in established firms than for entrepreneurship projects (Mezger, 2014).

$\mathrm{BMI}$ in an incumbent firm encompasses either the evolution of the current BM (Demil \& Lecocq, 2010) or the development of a new additive BM (Santos et al., 20I5), adjacent to the core business (Schneider \& Spieth, 20I3). The first case is quite well understood, referring to situations of BM change (e.g. Sosna, Trevinyo-Rodriguez, \& Velamuri, 20 I0) in which implementation could be difficult for actors (Demil \& Lecocq, 20I5), requiring, for instance, a progressive transition between the former and the new BM (Moingeon \& LehmannOrtega, 2010). Otherwise, incumbent firms develop new 
additive BM in various ways (Hacklin, Bjorkdahl, \&Wallin, 20 I 8), which could be distinguished in two different organizational configurations. On the one hand, some firms choose to adopt a new BM through the creation of new entities such as business units (Winterhalter et al.,20 I 7) or spin-offs (Frankenberger \& Sauer, 2019), whereby actors are dedicated to run the new business. On the other hand, a new BM can be developed within the established firm (Velu \& Stiles, 2013) by internal actors. Previous studies have raised questions about firms' performance when they compete with several BMs (Kim \& Min, 20I5) and studied how to manage a BM portfolio (Sabatier, Mangematin, \& Rousselle, 2010; Snihur \& Tarzijan, 20l8), leading to the formulation of advices for linking or splitting different activities (Markides, 2013; Markides \& Charitou, 2004). However, previous studies have provided limited explanation and conceptualization on how BMI is conducted within established firms that run an existing (core) activity (Frankenberger \& Sauer, 2019), except for the suggestion of a dedicated team to develop the new additive BM (Khanagh et al., 2014). In established firms, BMI teams encompass actors that are not necessarily entirely dedicated to the development of a new BMI. Consequently, established firms that innovate face tensions between new and existing business (e.g. Moingeon \& LehmannOrtega, 20 I0): developing a new BM within an incumbent firm requires specific attention from internal actors, which also operates other activities. Previous studies on the search for new BMs have noted several issues that are closely linked to attention, such as internal competition for resources (Aversa, Haefliger, \& Reza, 2017), ongoing paradoxical tensions between strategic temporary conflicting strategic goals (Smith, Binns, \& Tushman, 2010), or cognitive dependence on the prevailing BM (Laudien \& Daxböck, 2016). In established firms, actors are not necessarily completely dedicated to the search for innovation. However, identifying new signals or adopting a different perspective to elaborate new logics of value creation, delivery, and capture is costly in terms of attention. Consequently, tensions in resource allocation, in particular the available stocks of managerial efforts, may be more intense in established firms that intend to innovate their BM (Snihur \& Wiklund, 2019). While those tensions may be necessary to drive the transformation of businesses and organizations (Calori, 2002), they also bring attentional challenges that must be managed to ensure BMI success (Massa \& Tucci, 20I4). To further explore this aspect, we investigate the attentional implications of BMI.

\section{Attention challenges of BMI}

Attention is a mechanism of allocating cognitive and organizational resources (Simon, 1947), and a critical aspect of an organization's activities and performance (Cyert \& March, 1963; Hansen \& Haas, 200I). While it remains overlooked in the research on
BMs (Bjorkdahl \& Holmén, 20I3; Foss \& Saebi, 20I7), scholars have recently acknowledged attention as one of the most challenging aspects of BMI in incumbent firms (Frankenberger \& Sauer, 2019; Snihur \&Wiklund, 2019). Indeed, the existing studies reveal that attention is a critical driver for the generation of new ideas (Li et al., 2013) to detect changes in the firm environment (Yadav, Prabhu, \& Chandy, 2007) or to allocate persisting efforts to lead a BM innovation until its end (Frankenberger \& Sauer, 2019). However, attention is a scarce resource (Simon, 1947): firms have limited time and tangible resources (e.g. budgets) to address various issues. Moreover, organizational actors have limited managerial capacities and must arbitrate, consciously or not, where to distribute their efforts. Consequently, a BMI team may not simply address new ideas or relevant issues. Instead, different tensions emerge from limited attention.

A first source of tension emerges from the significant mass of information, issues, or ideas that must be addressed with limited resources (Piezunka \& Dahlander, 20 I 5). Indeed, developing a new BM relies on managers' ability to select relevant stimuli (Osiyevskyy \& Dewald, 2015). Nevertheless, information overload can interfere with the notification and selection of external stimuli (Weick \& Sutcliffe, 2008): the infinite scope of available information can paralyze BMI by preventing managers from distinguishing relevant signals (McMullen, Shepherd, \& Patzelt, 2009). While working to maintain their prevailing activities, actors may miss opportunities (McMullen et al., 2009; Shepherd et al., 2017) or neglect new information and ideas (Piezunka \& Dahlander, 2015). Furthermore, defining a new BM involves arbitration between a large flow of ideas coming from many stakeholders (Chesbrough \& Schwartz, 2007) since developing innovative ideas can be time-consuming ( $\mathrm{Li}$ et al., 2013; Vuori \& Huy, 2016).

In incumbent firms, a second source of tension lies in the coexistence of the firm's existing activities and the development of new ones (Walrave, Romme, Van Oorschot, \& Langerak, 2017; Yadav et al., 2007). On the one hand, some studies suggest that the prevailing BM allows synergies with the new BM (Sabatier et al., 20I0). On the other hand, the literature also suggests that the prevailing BM may impede innovative initiatives (Chesbrough, 20l0) by acting as a 'dominant logic', that is, cognitive schemas that influence the way managers select and interpret information (Massa et al., 2017). At an organizational level, the prevailing BM distributes firms' attention in favor of existing activities: as developing new ideas may be time- and budget-consuming, innovative BM can be conflictual with managers' day-to-day activities (Chesbrough \& Rosenbloom, 2002).

The literature thus provides significant evidence of tensions in allocating established firms' attention without explicitly addressing the role of attention in BMI. To address this gap, we turn on the ABV as a promising framework through which to gain insights into the process of BMI. 


\section{An attention-based view of BMI}

The ABV is a theoretical perspective that conceptualizes how issues are selected and formulated by organizational actors and explains why and how those issues lead to concrete firm moves. It defines attention as the "noticing, encoding, interpreting, and focusing of time and effort by organizational actors on a limited set of issues and answers" (Ocasio, 1997, p. 189). While the ABV is not the only theoretical approach to attention, it constitutes a particularly interesting conceptual framework for addressing the logics of attention at work in a BMI process. The ABV results from the articulation of two other main streams (Ocasio, 1997): the cognitive approach (Weick \& Sutcliffe, 2006), which focuses on the interpretative mechanisms that orientate actors' attention, and the structuration approach (Cyert \& March, 1963), which considers how organizational structures distribute scarce resources. Therefore, the ABV provides a particularly relevant framework through which to apprehend organizational processes (Orvain, 2014) such as $\mathrm{BMI}$ by helping to conceptualize the mechanisms that link a firm's strategic choices with managerial activities and interpretations (Shepherd et al., 20 17). Furthermore, adopting an ABV provides two conceptual opportunities to unfold BMI.

First, the ABV offers a refined framework for understanding BMl's tensions in established firms by distinguishing several mechanisms to arbitrate between existing activities and innovation. Indeed, the $A B V$ invites the consideration of the varieties of attention that intervene in the process of BMI by addressing three forms of attention (Ocasio, 20l I; Orvain, 2014). Selective attention encompasses the scanning and selection of objects in the environment. Selective attention shapes innovative processes by focusing on specific details that change perceptions of the environment (Naveh \& Erez, 2004) or by determining the scope of the internal and external information used to feed new ideas (Dahlander \& O'Mahony, 2016). Engaged attention refers to the focus on deliberate managerial efforts to enhance the understanding of a specific object (Weick \& Sutcliffe, 2006). Engaged attention is critical in the development of ideas through activities such as brainstorming (Li et al., 2013). Distributed attention implies the allocation of organizational resources in time and space toward pre-established directions (Rerup, 2009). It determines, for instance, which activities will receive investments (Surroca, Prior, \& TribóGiné, 20 I 6). Distributed attention conditions which aspect of the new BM will receive resource commitment. Thus, the ABV provides a refined framework for understanding the BMI process as developing new ideas may imply different mechanisms of arbitrating between existing activities and innovation, underpinned by fluctuating activities (Li et al., 2013).

Second, the ABV framework provides a particularly useful lens through which to track BMI, especially in the early stages as actors may not yet specifically realize that they are undertaking BM innovation. Following ABV principles, we consider BMI to be a 'situated' process (Ocasio, 1997): attention is shaped by the contextual conditions in which the organizational actors are embedded. This consideration is important since a BMI team's time and efforts are driven by preexisting activities and structures, such as organizational goals (Greve, 2008), strategic agendas (Dutton, 1997), previous organizational choices, internal procedures and norms, or existing infrastructures (Joseph \& Ocasio, 2012). Until the new BM is formalized or fully implemented, the emergence of its different components may remain quite intangible or fuzzy. Consequently, internal BMI teams may require specific organizational conditions to allow the development of new ideas (Rhee \& Leonardi, 20 I8). Variations in attention can explain how new ideas enter BMI team's scope, particularly intense creative activities, or in changes in the way they allocate resources of the firm. To track attention, the ABV provides various tangible indicators (Gavetti \& Ocasio, 2015), such as the content of communications (D'Aveni \& MacMillan, 1990), meetings and managerial activities dedicated to an issue (Stanko \& Beckman, 20I5), or budget allocation.

To conclude, an attention-based lens emphasizes two explanatory mechanisms of BMI in established firms. First, unpacking the forms of attention underpinning BMI can help in conceptualizing how a new BM emerges from activities embedded in the prevailing BM (Rhee \& Leonardi, 20 I8). Second, considering the various obstacles within incumbent firms (Frankenberger \& Sauer, 2019), examining variations of attention along the process can enhance knowledge regarding the conditions to undertake $\mathrm{BMI}$. Accordingly, we formulate the following research question: how does internal actors' attention shape the development of a new additive BM in an established firm?

\section{Methodology}

We chose to investigate the attentional mechanisms underlying $\mathrm{BMI}$ through an explorative study relying on a qualitative approach. This article is based on the case of new BM development undertaken by Consultor, a consulting company. We study how Consultor developed a new BM in the context of a project called the 'New Offer Project' (NOP). Our longitudinal study relies on observations over a 40-month period completed by interviews and archival data.

\section{Research site}

We relied on a single case study (Yin, 2013) because our research question addresses a complex and underexplored phenomenon that requires a rich description and an in-depth understanding of the context. 
We selected the case of Consultor, which is a small French management consulting firm based in Paris. The company has several small branches in Europe and Canada. Its main activities encompass consulting services for large companies. Founded in 2010 , the firm has a staff of 52 consultants and has been growing each year - achieving in 2016 a turnover of more than $€ 6$ million. In 2013, while Consultor was working exclusively for large corporations, top managers decided to develop a new consulting offer for small and medium enterprises (SMEs). They named a team of consultants (NOP team) in charge of the development of the 'NOP'. The NOP includes several differences and innovations that significantly differ from Consultor's prevailing BM, such as customer segment, partners, or revenue model. Such changes include innovations in terms of services and processes, which characterize BMI (Bjorkdahl \& Holmén, 20I3). The NOP does not aim at replacing the prevailing BM but rather hopes to develop a new additive BM (Santos et al., 2015) at Consultor. Over months, the NOP team has worked on the new offer to develop its BM. However, it is important to underscore that NOP members do not use the concept of BM, not even the word 'business model', any definition or framework.

Following Eisenhardt and Graebner's (2007) recommendations for sampling a single case, we argue that this case is particularly relevant for three reasons. First, the case context highly conductive to BM innovation (Massa \& Tucci, 20I4): as the consulting industry is a mature industry, growing harsh competition pushes consulting firms to constantly innovate to maintain their competitive advantage (Avadikyan, Lhuillery, \& Negassi, 2016). Second, by choosing a small organization in which top management is involved in $\mathrm{BMI}$, we can observe the new BM development in a relative exhaustive way across the different levels of the firm. The company's small size and the focus on the NOP leading team - which is composed of top managers and a few consultants - offered full access to rich and relevant data for the study of attention. The internal position of one of the researchers allowed him to frequently interact with top management and to observe daily activities and decision-making.

Third, we used several sampling criteria to characterize the "revelatory potential" of the NOP team's configuration (Gioia, Corley, \& Hamilton, 2013, p. 15). The first criterion was the ability to reveal the attentional tensions that emerge from an internal BMI team: the NOP team was both involved in the operation of existing activities and new BM development and thus needed to differentiate between prevailing and new BM logics. The second criterion concerned the possibility of observing $\mathrm{BMI}$ at an early stage to better understand how new ideas emerge and are developed: we were able to follow the project from the first steps of its development. The third criterion was the multiplicity of the stakes that drove the new BM development because the NOP was not only driven by profit-seeking. Indeed, actors also considered that such consulting services could contribute to economic development by supporting small businesses.

The NOP was thus a perfect opportunity to observe how actors allocated their attention to address tensions between existing and additive BM as suggested in the literature.

\section{Data collection}

The single-case design of the study follows an ethnographic type (Atkinson \& Hammersley, 1994). One of the authors spent 3 days per week in the field for 60 months through his internal position at Consultor. This period allowed him to participate to the NOP development as he was involved in all related activities (e.g. meetings with partners and customers, and internal workshops) and in the organization's social life (e.g. interactions with internal and external stakeholders, informal conversations, and events). Our study constituted an opportunity to observe BMI in an established firm 'as it happens' rather than through an a posteriori reconstitution (Demil \& Lecocq, 2015). We used an insider/outsider approach (Gioia, Price, Hamilton, \& Thomas, 2010) to maximize the data collection provided by the insider position. This configuration enabled the study to confront the insider view with the outsider one, allowing us to obtain the right distance in the field and to increase the reliability of our findings.

The BMI was informed by both primary and secondary data. First, the first author kept a sibylline research diary (Laszczuk \& Garreau, 2018) over the period of observation that allowed to take notes systematically and to share it with the second author (e.g. Bourgoin, Bencherki, \& Faraj, 2019; Bourgoin \& Harvey, 20l8). The data collection setup allowed for assistance and participation in 98 events of NOP development over 60 months and for the recording of a substantial part of it (45 events, representing $68 \mathrm{~h}$ of audio recordings see Appendix 1). Moreover, over the period, the immersed researcher shared the everyday life of the organization's members. Second, eight formal semi-structured interviews were performed and recorded (see Appendix 2). We interviewed the key actors from the NOP and Consultor top management several times at different development stages of the project. These interviews allowed us to complete our understanding of the observed events and to gather more explanations from the main actors. Furthermore, documents related to the projects (timing and e-mails) or to the company (website, articles, and corporate presentations) were collected (Figure I).

Although the NOP was officially launched in 2013, the case analysis shows that anterior events had inspired the chief executive officer (CEO) before Consultor's creation (particularly between 2000 and 2012). Therefore, we also relied on retrospective interviews to investigate those anterior events. Table I summarizes the collected data. 


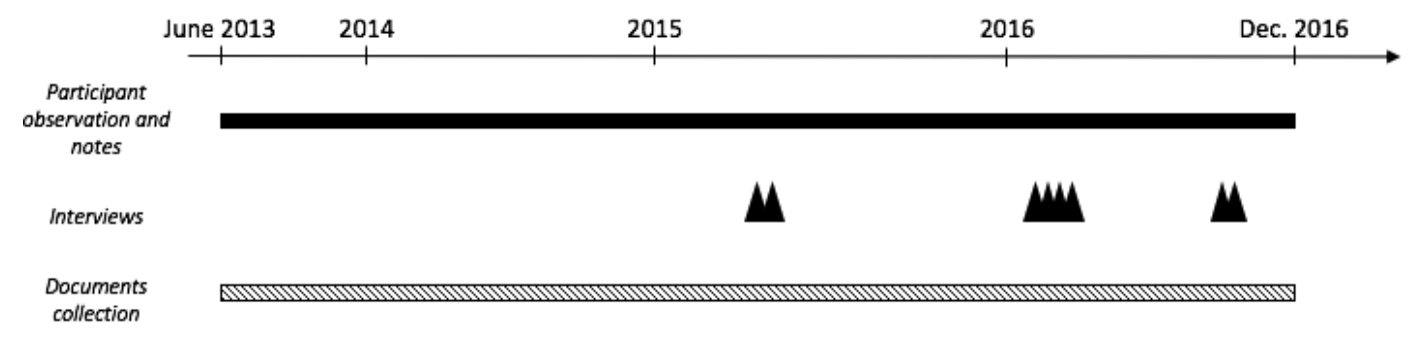

Figure I. Data collection process

Table I. Data collection and use in the analysis

\begin{tabular}{|c|c|c|}
\hline Data sources & Type of data & Use in the analysis \\
\hline \multirow[t]{2}{*}{ Observations } & $\begin{array}{l}\text { Field notes from } 98 \text { events of NOP's development (approxi- } \\
\text { mately } 420 \text { pages): detailed records of interactions, conversa- } \\
\text { tions and consequences. }\end{array}$ & $\begin{array}{l}\text { To identify attentional objects and to characterize the NOP team's } \\
\text { attention (distribution of time and effort). }\end{array}$ \\
\hline & Informal observation of everyday activities in the company. & $\begin{array}{l}\text { To be acclimatized to the context and drive data collection on relevant } \\
\text { events and interactions. }\end{array}$ \\
\hline Meetings & $\begin{array}{l}\text { Transcribed audio recordings from } 47 \text { meetings (approximately } \\
68 \mathrm{~h}-2,114 \text { pages) on the new offer development. }\end{array}$ & $\begin{array}{l}\text { To precisely track the NOP team's attention (words used, the } \\
\text { interactions during meetings, and the elements that are used later in } \\
\text { the development of the offer). }\end{array}$ \\
\hline \multirow[t]{2}{*}{ Interviews } & $\begin{array}{l}\text { Transcribed interviews with different stakeholders in the new } \\
\text { offer development project (eight taped interviews, approxi- } \\
\text { mately 9:30 h- } 574 \text { pages). }\end{array}$ & To analyze actors' interpretations and intentions during the NOP. \\
\hline & Informal interviews with Consultor's staff. & $\begin{array}{l}\text { To understand the context.To grasp informal relationships between } \\
\text { people. }\end{array}$ \\
\hline \multirow[t]{2}{*}{ Archival data } & $\begin{array}{l}\text { Company-related documents: web sites, corporate presenta- } \\
\text { tions, internal presentations (approximately } 60 \text { pages). }\end{array}$ & $\begin{array}{l}\text { To consider the identity and economic context in which the new offer } \\
\text { is developed. }\end{array}$ \\
\hline & $\begin{array}{l}\text { Project-related documents: minutes, correspondence with } \\
\text { stakeholders, customers' presentations, and others (approxi- } \\
\text { mately } 200 \text { pages). }\end{array}$ & $\begin{array}{l}\text { To trace the new offer development steps: from ideation to } \\
\text { formalization. }\end{array}$ \\
\hline
\end{tabular}

NOP: New Offer Project.

\section{Data analysis}

Our analysis comprised four main steps, which consisted in moving back and forth between our empirical data and the $\mathrm{ABV}$ literature to reconstitute the process of BMI.

\section{Step I. Chronological narrative database}

The first step of analysis aimed at revealing the chronology of $\mathrm{BMI}$ through a general narrative of the case (Nigam \& Ocasio, 2010). To achieve this, we constructed a narrative database (Langley, 1999; Van De Ven, 1992). We identified all incidences, that is, event meeting reports and activity reports, from 2013 to 2016 , and described the nature of the activities and the topics of discussions. We defined an 'incidence' as an event delimited in time and space (Van De Ven, 1992) that occurred within the scope of NOP team's daily activities during the period. This step allowed us to reconstitute the process of BMI by ordering and characterizing events in a chronologic incidence database.
At this point, no clear delimited phase emerged from this analysis. Our data suggested that the new BM emerged progressively, while the NOP team's attention navigated across several objects of attention over the period. Thus, instead of analyzing $\mathrm{BMI}$ as one single sequence of constructing a new BM as a whole, we apprehended the process as a series of sequences driven by specific objects of attention, as described in step 2 .

\section{Step 2. Division of the material according to seven attentional sequences}

We thus divided our material according to seven distinct 'attentional sequences'. This step consisted of identifying and delimiting categories of topics that received the NOP team's attention over the period. To generate those categories, we drew upon an inductive analysis for building a data structure (Gioia et al., 2013). First, we reviewed our raw data to generate a descriptive list of topics addressed by the NOP team while developing the new offer. Second, we gathered similar 

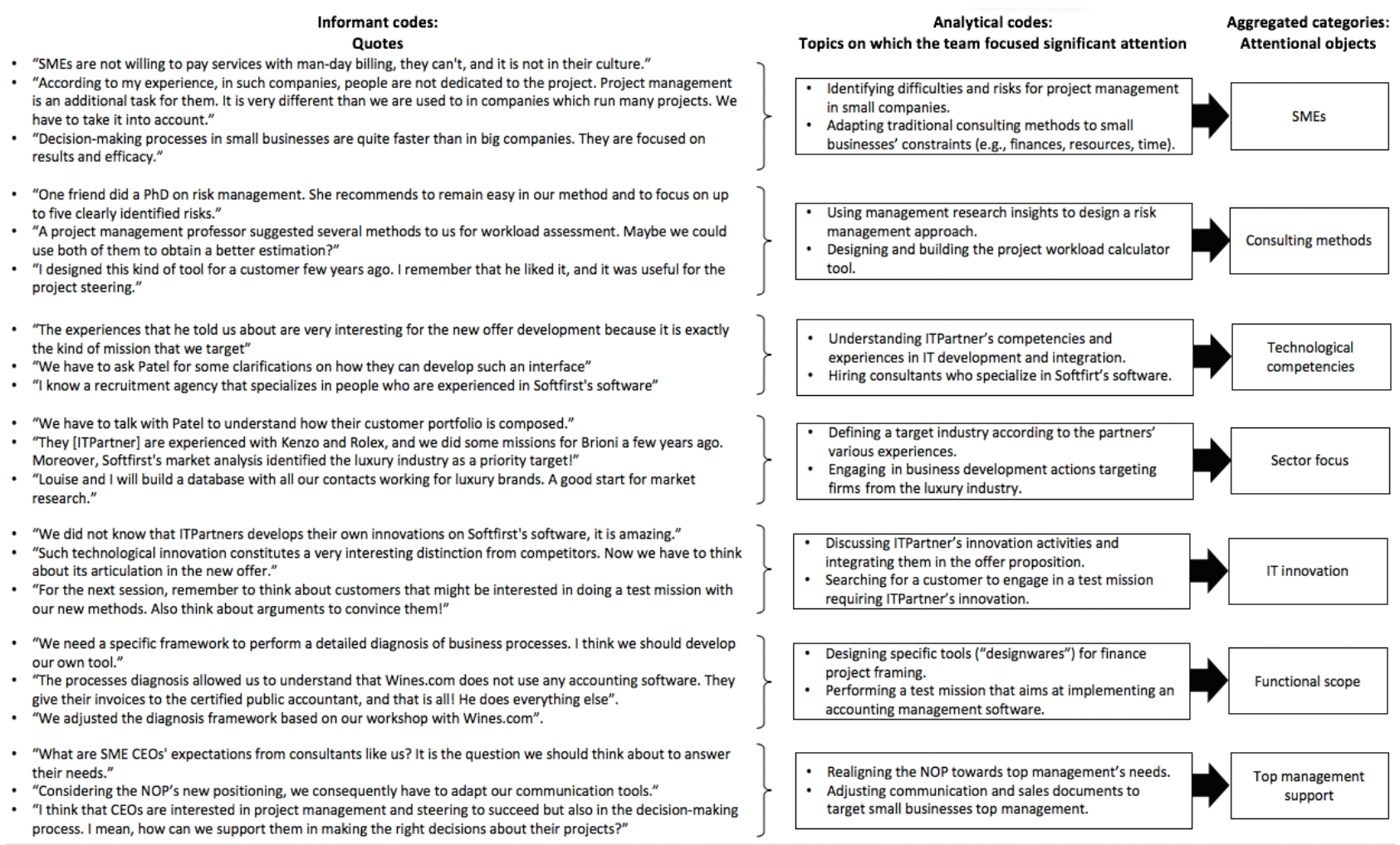

Figure 2. Data structure

${ }^{a}$ Attentional objects are named according to actors' vocabulary in the field.

topics into analytical codes. Third, we aggregated those analytical codes into seven general categories, which reflect the general topics addressed by the NOP team. In line with the ABV, we called those aggregated categories 'attentional objects' as they reflect a coherent set of issues that entered the NOP team's repertoire and received significant attention. Figure 2 shows the data structure that allowed for the identification of the seven attentional objects.

Those seven attentional objects provided a convenient grid for categorizing our data in terms of attention allocation. We could divide our narrative database into seven coherent sequences, which gathered the database incidences addressing a consistent object of attention over time, as summarized in Table 2.

This division of our material allowed us to clearly track how the NOP team distributed their time and effort toward one delimited object, as explained in step 3.

\section{Step 3.Thematic coding of attentional sequences}

We then coded the incidences of each attentional sequence through an analytical grid, which was derived from both the ABV framework and the BM literature. Coding an incident encompassed two aspects: first, identifying the form of attention allocated to the attentional object, and, second, characterizing the construction of the new BM.

First, coding forms of attention involved characterizing how the NOP team members distributed their time and efforts toward each attentional object. We used Ocasio's (20II) typology of attention, which distinguishes three forms of attention (selective, engaged, and distributed). Based on the ABV framework, we constructed indicators that we used to code our data, as summarized in Table 3.

Second, coding the construction of the new BM consisted in identifying the evolution of the new offer that emerged from each attentional sequence. We drew on the conceptual dimensions from Osterwalder and Pigneur's (2010) Canvas, which was consistent with several of the previous academic studies on BMI processes (e.g. Berends et al., 20 16; Cortimiglia, Ghezzi, \& Frank, 2015). This analysis was necessary to reveal $\mathrm{BMI}$ as the NOP members did not explicitly mobilize the concept or the vocabulary of BMs during the BMI process.

\section{Step 4. Identification of attentional triggers through an axial analysis of turning point incidences}

Finally, as we found that the NOP team's attention varied over time, we examined the turning point incidences in our 
Table 2. Attentional objects in the NOP development

\begin{tabular}{|c|c|c|c|}
\hline \# & Attentional objects & Description & Consequences on the NOP \\
\hline $\mathrm{AOI}$ & $\begin{array}{l}\text { Small and medium } \\
\text { enterprises (SMEs) }\end{array}$ & $\begin{array}{l}\text { Through their experiences, Consultor's CEO } \\
\text { detects that small and medium enterprises (SMEs } \\
\text { have needs for consulting services. }\end{array}$ & $\begin{array}{l}\text { Due to their specific characteristics and needs, SMEs are } \\
\text { considered to be a business opportunity for consulting services, } \\
\text { and become the target of the NOP. }\end{array}$ \\
\hline $\mathrm{AO} 2$ & $\begin{array}{l}\text { Technological } \\
\text { competencies }\end{array}$ & $\begin{array}{l}\text { Consultor's CEO meets a new IT services } \\
\text { provider based in India that could be interesting } \\
\text { for consulting services to SMEs. }\end{array}$ & $\begin{array}{l}\text { Technological services to SMEs become a core part of the } \\
\text { NOP.As such, technological competencies are a central topic } \\
\text { for the NOP team. }\end{array}$ \\
\hline $\mathrm{AO} 3$ & Consulting methods & $\begin{array}{l}\text { Consultor's CEO perceives that its classic } \\
\text { consulting methods are inadequate for SMEs. }\end{array}$ & $\begin{array}{l}\text { Considered to be a way to respond to SMEs' needs and } \\
\text { constraints, the NOP team works to adapt its consulting } \\
\text { methods. Insights from the management research allow the } \\
\text { team to innovate as such. }\end{array}$ \\
\hline $\mathrm{AO4}$ & Sector focus & $\begin{array}{l}\text { The NOP team considers that focusing on a } \\
\text { single sector should be relevant for the NOP } \\
\text { positioning. }\end{array}$ & The team focuses the offer on SMEs from the luxury industry. \\
\hline $\mathrm{AO5}$ & IT innovation & $\begin{array}{l}\text { One partner presents its abilities for IT } \\
\text { innovation, which could be interesting for } \\
\text { consulting services to SMEs. }\end{array}$ & $\begin{array}{l}\text { IT innovation becomes a core aspect of the NOP to provide } \\
\text { to customers. }\end{array}$ \\
\hline $\mathrm{AO} 6$ & Functional scope & $\begin{array}{l}\text { Focusing on a specific functional scope is actually } \\
\text { considered to be the relevant way to introduce } \\
\text { the NOP on the market. }\end{array}$ & $\begin{array}{l}\text { The NOP team chooses to address companies' financial } \\
\text { functions (e.g. accounting and management control). }\end{array}$ \\
\hline $\mathrm{AO7}$ & $\begin{array}{l}\text { Top management } \\
\text { support }\end{array}$ & $\begin{array}{l}\text { Through their experiences, Consultor's } \\
\text { consultants detect that SMEs' top managers need } \\
\text { strategic support. }\end{array}$ & $\begin{array}{l}\text { The NOP team changes its view and decides to address SMEs' } \\
\text { top management through a service dedicated to strategic } \\
\text { support. }\end{array}$ \\
\hline
\end{tabular}

Table 3. Indicators of NOP team's attention

\begin{tabular}{|c|c|c|}
\hline Form of attention & Definition (from Ocasio, 20 I I) & Indicators \\
\hline $\begin{array}{l}\text { Selective } \\
\text { attention }\end{array}$ & Objects are selected and enter actors' repertoires of issues. & $\begin{array}{l}\text { A new topic appears in the NOP team's discussions: } \\
\text { (I) Formal meetings that mention the object } \\
\text { (2) Informal discussions in which the object is mentioned. }\end{array}$ \\
\hline $\begin{array}{l}\text { Engaged } \\
\text { attention }\end{array}$ & $\begin{array}{l}\text { Actors focus on intense cognitive efforts to enhance their } \\
\text { understanding of specific objects. }\end{array}$ & $\begin{array}{l}\text { The NOP team dedicates meetings and discussions to } \\
\text { develop ideas on the new topic: } \\
\text { (1) Number of months that include at least one meeting or } \\
\text { discussion about the object } \\
\text { (2) Object's weight in NOP meetings' agenda. }\end{array}$ \\
\hline $\begin{array}{l}\text { Distributed } \\
\text { attention }\end{array}$ & $\begin{array}{l}\text { Actors allocate organizational resources in time and space } \\
\text { toward pre-established directions. }\end{array}$ & $\begin{array}{l}\text { The NOP team reallocates existing organizational } \\
\text { resources (e.g. activities, tools, and budget) toward their } \\
\text { new ideas: } \\
\text { (I) Activities performed by the NOP team members (e.g. meeting } \\
\text { a customer, designing a tool) } \\
\text { (2) Organizational resources allocated to an attentional object } \\
\text { (budget, human resources, and material resources). }\end{array}$ \\
\hline
\end{tabular}

NOP: New Offer Project.

database (Nigam \& Ocasio, 20l0). Explaining why the NOP team's attention varied over time was challenging as it was embedded in many organizational and external structures that shaped their everyday actions. Indeed, observations and interviews suggested that the NOP members directed their efforts depending on external constraints, interactions, firm rules, processes, or goals. We systematically compared turning points (i.e. incidences in which we observed a change of attention) (Glaser \& Strauss, 2009) to highlight their similarities and differences across the seven sequences. This axial analysis allowed us to identify similar combinations of triggering mechanisms.

To conclude, our analysis led to the characterization of the process of $\mathrm{BMI}$ as the articulation of three dimensions: distinct attentional objects that receive successive forms of attention 
triggered by specific mechanisms. To ensure the trustworthiness of our analysis, we presented the findings to the actors. They validated our interpretations and provided additional information, which we integrated into the findings.

\section{Findings}

The BMI process led to the following additive BM. The NOP aimed at proposing new consulting services to a different customer segment (SMEs), which required the company to adapt the customers' relationships and the revenue model. Moreover, the new offer intended to adapt consulting services and methods. Unlike the prevailing BM, two partners directly participated to elaborate the value proposition. Consequently, resources and activities were adjusted to enable the creation, delivery, and capture of the NOP's value. We found that the BMI process unfolded in an emergent and ongoing way, through seven attentional sequences. In each of them, the NOP team addressed a specific attentional object (i.e. a new topic that was progressively developed as new aspects of the NOP BM) by successively allocating three forms of attention (selective, engaged, and distributed).

This section is structured in two parts. First, we describe the attentional sequences by showing how each form of attention drove the development of the new additive BM. Second, we examine the attentional triggers that explain the shifts of attention.

\section{$B M I$ process as a series of attentional sequences}

The attentional sequences encompassed three stages according to the form of attention that the NOP team allocated to the attentional object: selective, engaged, and distributed attention.
First, attentional sequences began with a stage of selective attention in which a new attentional object entered the scope of the NOP team's attention. The NOP team began mentioning a new topic related to a problematic aspect that they experienced in operating their current business. Those issues mainly concerned customer segments, key activities, or key resources of the NOP. However, at that stage, the NOP members formulated such aspects as fuzzy threats or opportunities that Consultor had not addressed or that were inadequately addressed by existing offers. Despite the fact that the NOP team acknowledged them as interesting facts, they identified no clear connection with their core activities. As long as they did not consider attentional objects as a relevant or top priority topic, the NOP members did not allocate any sustained effort to addressing them. Table 4 illustrates the selective attention stage in sequences $\mathrm{AOI}$ and $\mathrm{AO} 2$.

Second, attentional sequences moved to a stage of engaged attention in which the NOP team allocated intense effort to the attentional object through dedicated brainstorming meetings or workshops. The NOP members intensely discussed how they could derive a new way to generate business from the issues identified in the previous stage by mobilizing existing resources and activities: they envisioned how to conduct new activities, to address a new customer segment, or use particular resources to propose new services. Consequently, attentional objects were progressively formulated in terms of new ideas to enrich the NOP value proposition. Table 5 illustrates the engaged attention stage in sequences $\mathrm{AO}$ I and $\mathrm{AO} 5$.

Third, most attentional sequences proceeded with a stage of distributed attention in which the NOP team adjusted and deployed existing organizational resources in new directions to concretize their ideas. They reallocated budget and workforce to launch commercial actions or design a new billing system adapted to SMEs' financial means. For instance, the team

Table 4. Illustrations of selective attention stages ${ }^{a}$

\begin{tabular}{|c|c|c|c|}
\hline Sequence & Selective attention & Illustration & Impact on the NOP BM \\
\hline AOI SMES & $\begin{array}{l}\text { Through one of his missions, Bernard } \\
\text { discovers SMEs' specificities. He identifies } \\
\text { that this type of structure requires } \\
\text { consulting services. }\end{array}$ & $\begin{array}{l}\text { "At LabCorp, it was very short projects that we did from the } \\
\text { beginning to the end with the required collaboration of the } \\
\text { internal team for operational efficiency [...] So, yes these } \\
\text { experiences inspired our idea [the new offer for SMEs] such } \\
\text { as missions that we did for Medinnov for instance". (Bernard } \\
\text { - interview) }\end{array}$ & $\begin{array}{l}\text { SMEs constitute the } \\
\text { customer segment } \\
\text { targeted by the NOP. }\end{array}$ \\
\hline $\begin{array}{l}\mathrm{AO} 3 \text { Consulting } \\
\text { methods }\end{array}$ & $\begin{array}{l}\text { Based on consulting missions for SMEs, } \\
\text { Bernard and Laura detect that traditional } \\
\text { consulting methods are inadequate. Thus, } \\
\text { they consider that new methods must be } \\
\text { specifically designed to address SMEs' } \\
\text { needs and constraints. }\end{array}$ & $\begin{array}{l}\text { "It [innovative consulting methods] comes from market } \\
\text { characteristics and constraints, I mean, we wondered how } \\
\text { could we consult for them [small businesses]? It is with } \\
\text { this thought that we decided to improve the new offer } \\
\text { with innovations related to the consulting part. [...]Thus, } \\
\text { in a way, innovation came from market constraints". } \\
\text { (Laura - interview) }\end{array}$ & $\begin{array}{l}\text { New consulting methods } \\
\text { are key resources for the } \\
\text { NOP. }\end{array}$ \\
\hline
\end{tabular}

aNames and description of actors mentioned in tables and vignettes are indicated in Appendix 3. 
Table 5. Illustrations of engaged attention stages

\begin{tabular}{|c|c|c|c|}
\hline Sequence & Engaged attention & Illustration & Impact on the NOP BM \\
\hline $\begin{array}{l}\mathrm{AO} 2 \\
\text { Technological } \\
\text { competencies }\end{array}$ & $\begin{array}{l}\text { Bernard and Laura dedicate } \\
\text { discussions to explore how ITPartner's } \\
\text { skills could enrich the NOP's value. } \\
\text { They realize that combining IT and } \\
\text { consulting services could be } \\
\text { particularly relevant for SMEs. }\end{array}$ & $\begin{array}{l}\text { "The main origin [of the new offer] is the meeting with a } \\
\text { potential partner [ITPartner] with which we concurred:'so, } \\
\text { we make complementary stuff, with different action scopes, why } \\
\text { don't we do something together? We should'. [...] After all, } \\
\text { considering both their competencies for offshore IT } \\
\text { development and their ability to work efficiently for SMEs [...] } \\
\text { ITPartner constituted the ideal partner for this new offer". } \\
\text { (Bernard - interview) }\end{array}$ & $\begin{array}{l}\text { IT services are } \\
\text { integrated to the value } \\
\text { proposition of the NOP. }\end{array}$ \\
\hline $\begin{array}{l}\text { AO5 IT } \\
\text { innovation }\end{array}$ & $\begin{array}{l}\text { Patel [ITPartner CEO] presents his } \\
\text { firm's activities to the NOP team. } \\
\text { Following this presentation, the NOP } \\
\text { team considers that ITPartner's } \\
\text { innovation abilities could be relevant } \\
\text { for services dedicated to SMEs. }\end{array}$ & $\begin{array}{l}\text { "Today, we realized that ITPartner is not only a simple IT } \\
\text { services firm for offshoring as we initially interpreted but a } \\
\text { company with a real innovation strategy and ability. These latter } \\
\text { aspects allow ITPartner to contribute to the NOP value } \\
\text { proposition". (extract from the diary } 03 \text { November 20I5) }\end{array}$ & $\begin{array}{l}\text { IT innovation } \\
\text { constitutes a part of } \\
\text { the value proposition of } \\
\text { the NOP. }\end{array}$ \\
\hline
\end{tabular}

Table 6. Illustration of distributed attention stages

\begin{tabular}{|c|c|c|c|}
\hline Sequence & Distributed attention & Illustration & \\
\hline $\begin{array}{l}\text { AO6 Functional } \\
\text { scope }\end{array}$ & $\begin{array}{l}\text { According to the NOP new functional scope on } \\
\text { finance functions, Bernard names a manager who } \\
\text { he considers to be the right person to lead an } \\
\text { experimental project. Performing this test mission, } \\
\text { this manager operationally implements the NOP. }\end{array}$ & $\begin{array}{l}\text { "Bernard asked Jean to manage the mission at Wines. } \\
\text { com }[. . .] \text { Considering his experience, he is the right } \\
\text { man for the job: as a director, he is an experienced } \\
\text { consultant and a former chartered accountant". } \\
\text { (Extract from the diary } 25 \text { January } 2016 \text { ) }\end{array}$ & $\begin{array}{l}\text { Key resources are adjusted } \\
\text { to the new functional } \\
\text { scope of the NOP. }\end{array}$ \\
\hline $\begin{array}{l}\text { AO7Top } \\
\text { management } \\
\text { support }\end{array}$ & $\begin{array}{l}\text { According to the new services for top manage- } \\
\text { ment support, the NOP team defines a new } \\
\text { billing system for missions. }\end{array}$ & $\begin{array}{l}\text { "Bernard and Jean consider that man-day billing is } \\
\text { impossible for such missions. [...] A subscription } \\
\text { system for consulting services emerged as an } \\
\text { innovative idea to sell missions". (Extract from the } \\
\text { diary } 21 \text { July 2016) }\end{array}$ & $\begin{array}{l}\text { Revenue streams are } \\
\text { modified according to } \\
\text { new services proposed } \\
\text { to SMEs. }\end{array}$ \\
\hline
\end{tabular}

designed and implemented a kit of new consulting tools and methods to promote their new offer and to engage in missions for small businesses. At this stage, attentional objects were concretized through formal resources, activities, customer relationships, channels, partnerships, or revenue streams to implement the NOP BM.Table 6 illustrates the distributed attention stage in sequences $\mathrm{AOI}$ and $\mathrm{AO} 6$.

To summarize, our process analysis of the NOP development highlights $\mathrm{BMI}$ as an ongoing and emergent process, driven by several simultaneous or successive attentional sequences ( $\mathrm{AOI}$ to $\mathrm{AO} 7$ ). We note that those sequences were heterogeneous: some of them did not reach the distributed attention stage, or they had different temporalities. In the following section, we explain this heterogeneity by examining the conditions that allowed shifts in the NOP team's attention.

\section{Attentional triggers for the $B M I$ process}

Shifts in the NOP team's attention occurred only when a combination of two triggering mechanisms was met. We present each of these combinations by explaining how they emerged and how they generated a specific form of attention and provide illustrative vignettes.

Selective attention was triggered by $(I)$ an interaction between the NOP team and external or internal interlocutors in which (2) NOP members perceived a gap between their environment and their prevailing BM.

While Consultor's actors were daily confronted with a variety of information, we observed that they tended to select new attentional objects when they perceived a dissonance between their external environment and existing structures such as activities and rules deriving from the prevailing BM. Indeed, each attentional sequence began when at least one member from the NOP team noticed a discrepancy between their existing services, methods, or tools and an external stimulus.

In all sequences, this perception of dissonance came from interactions between the NOP team and internal or external interlocutors. Those interactions encompassed formal and informal meetings with customers or partners and discussions, seminars, or workshops involving other Consultor employees. For example, a customer could express a need that was uncovered by existing services, or a consultant could experience difficulties 
in applying existing consulting methods. Although most of those interactions were deliberately intended by the NOP team, we note that the initial intention was rarely to deliberately search for new ideas or to innovate. Interactions triggered the selection of a new attentional object because the source of the perceived dissonance was verbalized as a new issue to address (Vignette I).

Engaged attention was triggered by (I) a collective perception of the attentional object as a business opportunity leading to (2) a collective agreement of the possibility of addressing it.

Despite their entrance in the NOP team's scope of attention, new attentional objects did not instantaneously generate any innovative efforts. Instead, our data suggest that they could remain at a stage of 'pending problem' for a variable time (from several days to several years) by being occasionally mentioned during internal meetings. Indeed, the incubation phases systematically began from the moment the NOP team thought that they could address the new $\mathrm{AO}$ with their existing means (e.g. resources, tools, or skills). Once the NOP team formally acknowledged its ability to reconcile a discrepant $\mathrm{AO}$ with available repertoires, the intensity of attention towards the AO changed. For instance, the NOP team began to pay more intense attention to IT innovation when the team perceived a way to use IT innovation for consulting services. By perceiving the $\mathrm{AO}$ as an opportunity reachable through the existing $\mathrm{BM}$, the NOP team became more inclined to spend significant time and effort to address it.

Those collective realignments occurred through various situations. In some sequences (e.g. $\mathrm{AOI}, \mathrm{AO} 4, \mathrm{AO} 5$, and $\mathrm{AO} 6$ ), it took several meetings in which other ideas were discussed and eventually connected to the attentional object by one or several NOP team members. We note that most of those sequences implied meetings with internal members of Consultor to discuss information coming from an external interaction. Once integrated in the NOP's agenda, attentional objects received sustained cognitive efforts and time from the team (i.e. engaged attention) such as dedicated meetings, workshops, brainstorming sessions, or networking activities (Vignette 2).

Distributed attention was triggered by (I) a spontaneous managerial action followed by (2) positive external feedback. We did not find any official 'momentum' or any planned milestone in which the NOP team clearly decided to stop 'incubating' the idea and to begin implementing concrete actions. Instead, changes of attention occurred when one of the NOP team members spontaneously took the personal initiative to push for an organizational concrete 'move,' such as reallocating budget, material, or human resources to concretize the incubating idea into a new aspect of BM. We observe that these managerial initiatives occurred when the actors perceived new ideas to be consistent with the prevailing BM. In other words, they considered whether the organization and resources of the existing activities allowed for the implementation of new characteristics of NOP BM. In the sequences that did not reach the stage of distributed attention (AO4 and AO5), we noticed that no one undertook any managerial initiative. According to the NOP members' explanations, they perceived no consistency with their existing activities or received negative feedback that discouraged them from maintaining their efforts.

Thus, positive feedback was also decisive for distributed attention and the redeployment of organizational resources. Indeed, the NOP team members only launched their initiative

Vignette I. Trigger for selective attention in sequence AO6

In October 2015, the NOP targets SMEs from the luxury industry. They have developed a nonspecialized offer with consultancy services for projects concerning all types of topics.

One day, Bernard has lunch with a former customer, Nicolas, who became top manager in an SME. During a discussion about their professional activities, Bernard talks to Nicolas about the NOP: he exposes the main purpose and the offer's configuration. Nicolas expresses his interest: according to him, SMEs need management consulting; however, he finds most of the consultancy services inadequate for this type of firm.

Nevertheless, he is reluctant to accept the nonspecialized nature of the offer. He suggests that SMEs must enhance the efficiency and speed of their projects: in this regard, a nonspecialized method may not be relevant in helping SMEs. Indeed, efficacy and velocity require methods refined through experiences on similar projects. He also argues that a nonspecialized offer may not be credible from customers' point of view. Consequently, he suggests that instead of focusing on one industry, the NOP should target a functional scope (i.e. specific thematic projects).

"So he quickly mentioned something that reminded me. He said that: "ok, you based your argumentation on projects' realization speed - I noticed your accelerating options - so in that way there is something that you should take into account: you can quickly achieve a project that you already did somewhere else" [...] Thus, he said that instead of adopting an open approach on customers' needs, we should adopt a specialist position about a topic such as marketing or finance controlling [...] Thus, the discussion's conclusion is that we should think and identify a functional scope as a functional specialization of the offer, on which we are able to be experts". (Bernard - meeting extract 16 October 20I5)

Nicolas' feedback clashes with the way in which Bernard and the rest of the team envision the NOP. Initially, they had simply replicated an approach similar to Consultor's classic consultancy services, which did not include any functional specialization. However, after this lunch, Bernard recounts the event to the rest of the NOP team: from this moment, the idea of defining a functional scope will be a topic of discussion. 
Vignette 2. Trigger for engaged attention in sequence $\mathrm{AO} 6$

In October 2015, after Bernard relates his lunch with Nicolas to the rest of the NOP team, the topic of functional scope arises without any enthusiasm from the members. The idea of defining a specific functional scope in their new offer changes radically from their usual approach. However, after some discussion, they begin to glimpse possibilities of choosing a functional scope for the NOP: they imagine that the functional scope could be a main function or department of the firm (such as marketing, finance, or accounting). Based on Consultor's expertise, they find that they can identify the most relevant function for the NOP scope. At some point, the NOP members perceive the functional scope focus to be an opportunity to enhance the NOP in two ways:

(I) First, to target customers more precisely ('which actors of SMEs to address?')

(2) Second, to build new consulting methods, that is, specific tools for thematic projects (e.g. accounting software implementation), which may differentiate their offer from other competitors.

"Louise: does this new specialization not reassess the new consulting methods we developed? Bernard: no, no. On the contrary, it brings precision to everything: tools, the offer preparation, projects we target in companies, people we should talk with... According to the functional scope, we will meet the right directors". (Meeting extract 16 October 2015)

Vignette 3. Trigger for distributed attention in sequence $\mathrm{AO} 6$

In December 2015, Bernard considers that the NOP is now mature enough to launch a test mission. To do so, he must find a customer who will agree to participate in the test. However, this task is delicate: customers are not willing to pay for being a 'guinea pig' to test new consultancy services. Requests for this test mission may annoy customers: bernard admits that he is walking on eggshells.

In addition, Consultor is sponsoring an e-commerce start-up - Wines.com. One day, during a strategic steering committee, Bernard learns that the start-up needs a new accounting system. This need constitutes a perfect opportunity for a NOP test mission: bernard submit the idea to David,Wines. com's CEO. The latter is enthusiastic and considers it to be a real opportunity for his company. As the start-up cannot afford consultancy services, the deal is set for free (without fees). Wines.com's CEO is overjoyed and plans to work with Consultor's consultants. From this moment, the NOP team begins to dedicate concrete resources and to implement the ideas that had been developed.

"Bernard explained to us that David has accepted that we will perform a NOP test mission at Wines.com. The company apparently needs new accounting software, and they do not know how to choose the tool and implement it. [...] Bernard and Laura agreed to perform the mission for free only because it is for Wines.com, which is one of Consultor's partners". (Extract from the diary 30 July 20I5)

when they perceived an explicit supportive signal from the environment. In some cases, this perception was an ex-ante intuition from actors, which was confirmed or refuted afterwards by implementing the idea. In other cases, this perception came from customers' or partners' positive feedback (Vignette 3). Our data suggest that this change of attention occurred without explicitly acknowledging an innovation in the BM.The team did not officially label those actions as the launching of a new BM. In the moment, they expressed them as a simple implementation of new ideas derived from the attentional objects. Retrospectively, however, they acknowledged that they were indeed progressively developing an additive BM.

Table 7 provides a systematic analysis of those attentional triggers for all sequences.

Figure 3 provides an overview of the whole BMI process, structured by attentional objects, stages, and triggering mechanisms.

\section{Discussion}

By examining BMI through an attentional lens, this study provides several contributions. First, we conceptualize the attentional process that drives new BM development, providing new knowledge about BMI. Second, we highlight the insights obtained with regard to the $A B V$. Third, we discuss the practical implications of the study. We conclude by pointing out some limits and further research directions.

\section{Attention as a driver of BMI}

While the literature acknowledges that attention is a critical aspect to uncover in the BMI research (Bjorkdahl \& Holmén, 2013; Foss \& Saebi, 2017; Snihur \& Wiklund, 2019), few studies (except Frankenberger \& Sauer, 2019) have provided empirical explanations of how it shapes new BM development. In line with recent research agendas (Bjorkdahl \& Holmén, 2013; Foss \& Saebi, 2017), this study aims at shedding light on the role of attention for BMI in established firms (Berends et al., 2016; Demil et al., 20।5; Massa \& Tucci, 20।4), which face particular tensions in managing their attention (Kim, Kim, \& Foss, 2016). We unfold a three-phase attentional process that, applied to various attentional objects, drives the emergence and 
Table 7. Attentional triggers

Combination of triggering mechanisms leading to selective attention

\begin{tabular}{ll}
\hline Turning point Interaction with external or internal environment $\quad$ Perceived gap between environment and prevailing BM \\
incident
\end{tabular}

(AOI) SMEs

Bernard conducts consulting missions for SMEs.

Bernard perceives that SMEs have management consulting needs but are a customer segment that is untargeted by Consultor.

(AO2) Technological Bernard meets Patel, CEO of ITPartners. competencies

Bernard considers that to answer SMEs' needs, consultants' intervention should increase project speed. Consultants' specific technological competency is a way to raise project velocity whereas Consultor's team is technologically not specialized.

(AO3) Consulting Bernard conducts consulting missions for SMEs. methods

Bernard analyzes the fact that existing consulting methods are dedicated to big companies and, consequently, unsuitable for SMEs' needs and management modes.

(AO4) Sector focus Bernard, Laura, and Patel discuss the NOP's target Although the NOP targets SMEs from all industries, Softfirst with Softfirst's managers.

(AO5) IT Bernard, Louise, and Jacques have a business lunch innovation with Patel. encourages Bernard, Laura, and Patel to focus on a particular sector. Patel's presentation of ITPartner's technological innovations affects the NOP team's perception: ITPartner is not a simple technological subcontractor for offshoring.

(AO6) Functional Bernard meets Nicolas to discuss the NOP. scope

For project efficiency and speed, Nicolas advises focusing the NOP on a functional scope (i.e. projects' thematic specialty). This feedback contradicts the NOP team, which believes that the NOP must be nonspecialized.

(AO7)Top The NOP team organizes a workshop for NOP

Other consultants advise that the NOP should not address managers with regard to their project implementation but rather target top Management development with other Consultor's consultants. management for the management of the firm's project portfolio.

Combination of triggering mechanisms leading to engaged attention

\begin{tabular}{ll}
$\begin{array}{l}\text { Turning point } \\
\text { incident }\end{array}$ & $\begin{array}{l}\text { Collective perception of the object as a business } \\
\text { opportunity }\end{array}$ \\
\hline (AOI) SMEs & $\begin{array}{l}\text { Considering the large number of SMEs, Bernard and } \\
\text { Laura consider that this customer segment could } \\
\text { become a growth driver for Consultor's consulting } \\
\text { activities. }\end{array}$
\end{tabular}

(AO2) Technological Bernard and Laura consider technological compecompetencies

(AO3) Consulting methods

(AO4) Sector focus

(AO5) IT innovation

(AO6) Functional scope

(AO7) Top Management Support tency to be a good way to enrich the NOP value. Bernard considers adapting consulting methods to SMEs to be an opportunity to differentiate Consultor from its competitors.

\section{Consultor's top management perceives the sector} focus to be a good way to differentiate the NOP on the consulting market.

The NOP team is impressed by ITPartner's innovations: it could reinforce the NOP's value proposition for customers.

The NOP team perceives the functional scope focus to be a way to increase NOP precision in two ways: first, for targeting customers (the part of the firm to address); second, for consulting methods building. Bernard and Laura think that targeting SMEs' top management is a good way to be close to the customers' needs.
Collective perception of the possibility to address the object

Bernard and Laura's discussions lead them to plan to build a dedicated offer for this type of company.

Bernard and Laura think that Consultor can acquire technological competency collaborating with ITPartner.

The NOP team believes that they can build innovative consulting methods based on their experiences and using management research insights.

Bernard, Laura, and Patel plan to identify the NOP focus sector considering Consultor's and ITPartner's experiences and networks.

Partnership with ITPartner allows their IT innovations to be included in the NOP's value proposition.

The NOP team wants to choose the NOP functional scope according to the main Consultor's expertise.

The NOP team considers Consultor's experienced resources (such as directors and senior managers) to have legitimacy and credibility to address top managers. 
Table 7 (Continued). Attentional triggers

Combination of triggering mechanisms leading to distributed attention

\begin{tabular}{|c|c|c|}
\hline $\begin{array}{l}\text { Turning point } \\
\text { incident }\end{array}$ & Spontaneous managerial action & Positive external feedback \\
\hline$(\mathrm{AOI}) \mathrm{SMES}$ & $\begin{array}{l}\text { Bernard and Laura decide to build a dedicated offer to } \\
\text { address SMEs as a new target for consulting activities. }\end{array}$ & $\begin{array}{l}\text { Bernard and Laura explain their idea of the SMEs' dedicated offer. } \\
\text { A partnership between Consultor and ITPartner is settled. }\end{array}$ \\
\hline $\begin{array}{l}\text { (AO2) Technological } \\
\text { competencies }\end{array}$ & $\begin{array}{l}\text { Identifying complementarity between expertise, } \\
\text { Bernard and Laura propose to ITPartner a partner- } \\
\text { ship with the NOP. }\end{array}$ & $\begin{array}{l}\text { Patel accepts the partnership. Consultor's consultants and ITPartner's } \\
\text { engineers discuss their complementarity in an operational way (i.e. } \\
\text { how they can work together). }\end{array}$ \\
\hline $\begin{array}{l}\text { (AO3) Consulting } \\
\text { methods }\end{array}$ & $\begin{array}{l}\text { Identifying reusable knowledge from former missions, } \\
\text { Bernard hopes that the NOP team could begin to } \\
\text { concretely build new consulting tools adapted to SMEs. }\end{array}$ & $\begin{array}{l}\text { The first tools are presented to a potential customer, which has an } \\
\text { enthusiastic reaction. }\end{array}$ \\
\hline $\begin{array}{l}\text { (AO6) Functional } \\
\text { scope }\end{array}$ & $\begin{array}{l}\text { Bernard wants the NOP team to perform a test } \\
\text { mission: he proposes a free mission to Wines.com } \\
\text { (an SME) that is a Consultor partner. }\end{array}$ & $\begin{array}{l}\text { The Wines.com's CEO accepts the proposition of Consultor to } \\
\text { perform a test mission for his company. }\end{array}$ \\
\hline $\begin{array}{l}\text { (AO7) Top } \\
\text { Management } \\
\text { Support }\end{array}$ & $\begin{array}{l}\text { Bernard asks to the NOP team to work on the NOP's } \\
\text { commercial and marketing tactics using knowledge } \\
\text { from previous missions linked to strategic support } \\
\text { (e.g. missions for project portfolio management). }\end{array}$ & $\begin{array}{l}\text { The NOP is presented to a potential customer with the aim of having } \\
\text { Consultor perform a mission for him. }\end{array}$ \\
\hline
\end{tabular}

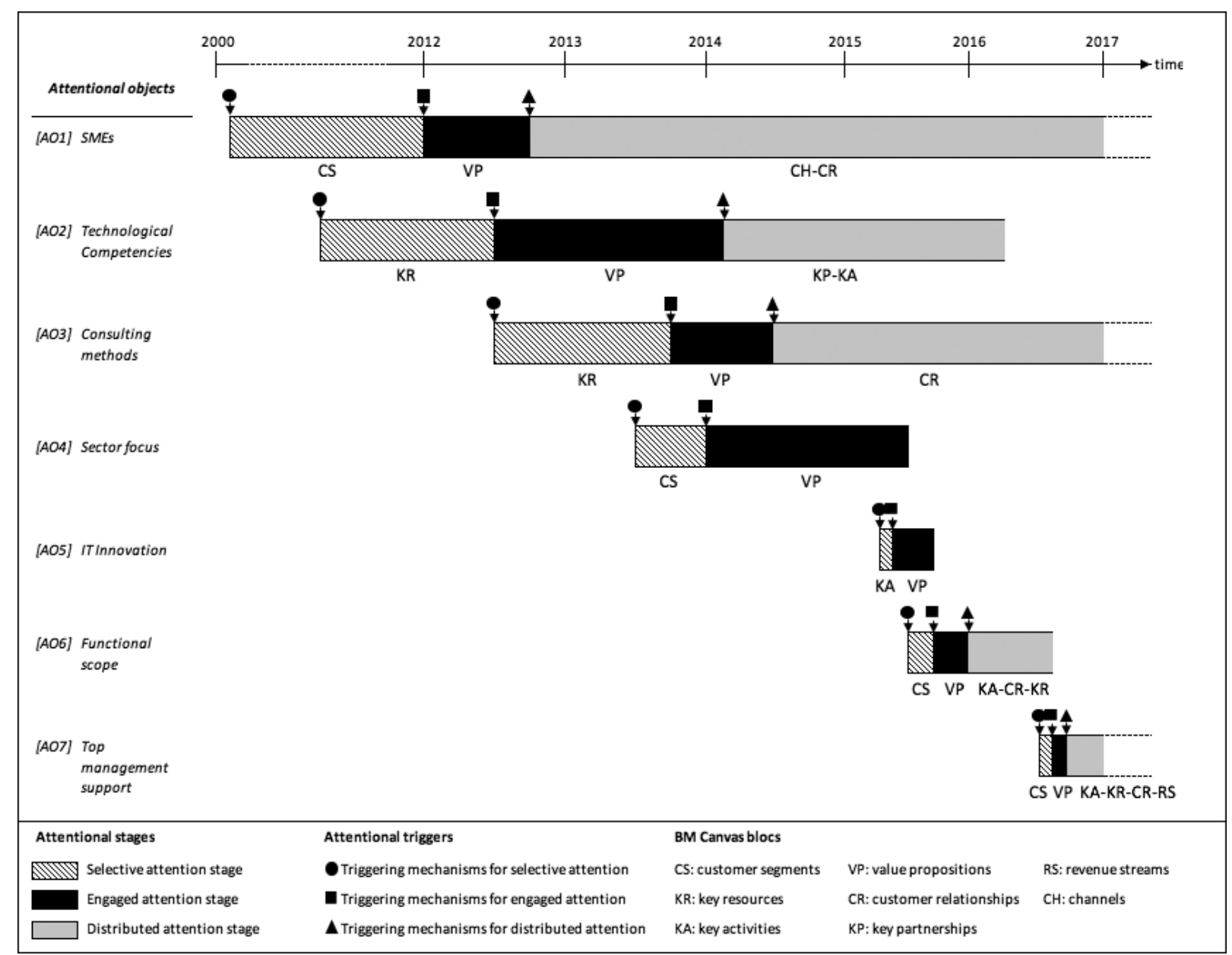

Figure 3. BMI as a succession of attentional sequences 


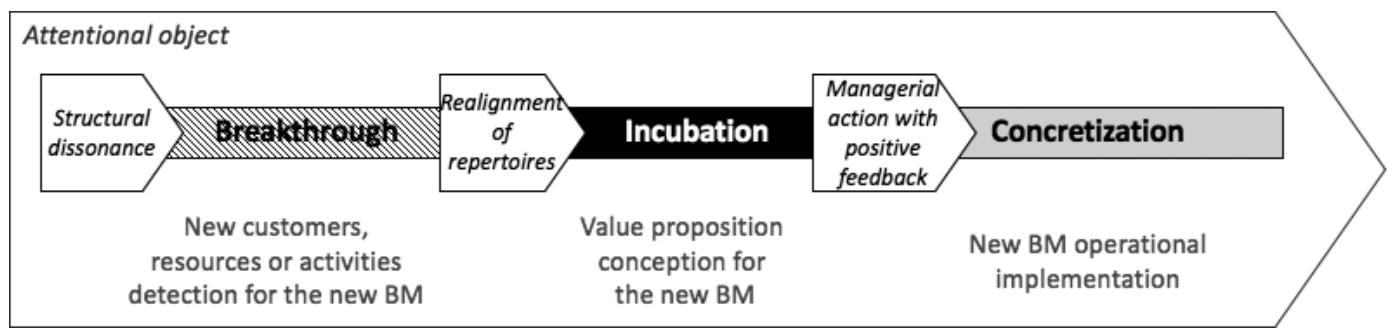

Figure 4. The attentional process driving BMI

development of a new BM over time. Triggered by specific mechanisms, shifts of attentional forms allow actors to select, develop, and concretize ideas for new BM development (see Figure 4).

First, we highlight a 'breakthrough phase' in which actors turn their attention towards addressing new customer segments, the use of new resources or activities to conduct in the new BM. Actors' social interactions create a perceived gap between the prevailing BM and their environment and constitute a 'structural dissonance', triggering selective attention that fosters the selection of a new object into the actors' scope. The new ideas derived from this attentional object constitute starting points for new BM development.

Then, our study reveals an 'incubation phase' in which actors conceive the new BM's value proposition. The perception of a reachable business opportunity operates as a 'realignment of repertoires', triggering engaged attention for actors' new idea exploration. During incubation, actors pay particular attention to the implications of such value proposition, that is, to the required adjustments of other BM aspects to implement such new ideas. This step is critical for the additive BM development because the actors envision the new value proposition's feasibility regarding their existing means (e.g. resources, experiences, skills, or networks).

Finally, we unfold a 'concretization phase' in which the actors operationally adjust and implement the additive BM according to the new value proposition. Adjustments emanate from a 'spontaneous managerial action with a positive feedback' from external stakeholders (e.g. customers or partners). Our findings indicate that managerial actions are conditioned to managers' perceptions of consistency between the additive and the prevailing BM. This latter, as a dominant logic (Bettis \& Prahalad, 1995; Massa et al., 2017), defines existing organizations, activities, and resources that actors use to implement the new additive BM.

Unpacking the attentional mechanisms of new additive BM development in an established firm provides two main contributions. First, it enhances the knowledge of BMl by revealing the ongoing and emergent nature of the process. Second, it invites the BMI literature to reconsider the critical role of the prevailing BM.

\section{BMI as an ongoing and emergent process}

While previous literature has considered new BM development to be a deliberate managerial willingness to innovate (Martins, Rindova, \& Greenbaum, 2015; Snihur \& Wiklund, 2019), our study reveals that it relies on both deliberate and emergent processes, similar to other organizational processes, such as strategy construction (Mintzberg \& Waters, 1985). We depict BMI in established firms as an ongoing process that involves different forms of attention (selective, engaged, and distributed), allowing new objects to progressively 'feed' the innovation process. Our findings indicate that BMI calls for a combination of actors' behaviors using both external and internal insights rather than relying only on exogenous knowledge (Snihur \& Wiklund, 2019). Once new ideas emerge from actors' interactions with the external environment, their implementation requires deliberate allocation of internal time and effort. Furthermore, by revealing attentional triggers, we contribute to the recent call to specify what initiates an attention shift in BMI (Frankenberger \& Sauer, 2019). Our study provides evidence that BMI is not only a matter of actors' efforts or willingness to innovate. Instead, BMI attentional shifts require specific combinations of triggers: those triggers imply external interactions or stimuli and spontaneous managerial moves that are emergent rather than deliberately planned actions.

\section{From differing to consistency: Actors' use of the prevailing BM}

The attentional lens adopted in this study provides insights into the critical role of the prevailing BM, which challenges existing theoretical discussions on BMI in established firms. While previous studies considered the prevailing BM as a 'dominant logic' that can impede actors to see their business in a new way, we observe that it is a crucial element for the development of the new additive BM. Indeed, our findings show that the prevailing BM constitutes a frame of reference that drives actors' attention during the BMI process, through which they become aware of the discrepancies between their external environment and their internal activities. The prevailing BM is also used 
as a frame of reference to solve the tensions that emerge from the development of a new additive BM while continuing existing activities (Velu \& Stiles, 2013).

First, in breakthrough stages, actors tend to differ from the prevailing BM by selecting dissonant objects. These findings highlight how BMI occurs despite the existence of a dominant logic inherent in an established firm (Chesbrough, 20l0; Massa et al., 2017; Tripsas \& Gavetti, 2000). More precisely, Chesbrough and Rosenbloom (2002) argued that the prevailing BM drives decision processes since decision-makers tend to filter information that exclusively fits with this dominant logic. In contrast, our study showed that actors can select dissonances between the prevailing BM and their external environment, driven by their natural tendency to search for consistency in their actions (Bem, 1972; Festinger, 1957). Moreover, those results are consistent with Saebi, Lien and Foss's (2017) study, which shows that firms are more prone to BMI when they face threats instead of opportunities: when actors perceive the weaknesses of their existing structures, they spend time and effort designing creative solutions and thus develop new BM (Massa \& Tucci, 2014; Schneckenberg, Velamuri, Comberg, \& Spieth, 2017). Conversely, in the incubation phase, actors design new additive BM value propositions seeking consistency with the prevailing BM.Through such consistency, actors ensure that they can (prevailing BM defines the firm's means) and know how (prevailing BM constitutes a dominant logic) to concretize new ideas. A lack of perceived synergies with the prevailing BM explains why some attentional objects are dropped before their concretization. Finally, in the concretization phase, actors use the prevailing BM (e.g. the firm's resources, activities, or skills) to operationally implement the new BM. While the literature acknowledges external (with the environment) and internal (between components) consistency of BM (Demil \& Lecocq, 20 I0; Morris, Schindehutte, \& Allen, 2005), our study reveals that inter-BM consistency is required for a new additive BM development in established firms. These observations extend Berends et al.'s (2016) conclusions about synergies between the prevailing and new BM by specifying how the prevailing BM is directly or indirectly used to construct the new one. Overall, our study highlights how the 'path dependency' effect arising from the prevailing BM (Bohnsack, Pinkse, \& Kolk, 2014; Chesbrough \& Rosenbloom, 2002; Demil \& Lecocq, $2010)$ determines managerial thinking and influences the development of a new BM. Consequently, BMI is not necessarily a way to avoid established firms' inertia and does not guarantee strategic renewal (Snihur \&Wiklund, 2019).

\section{Contributions to the ABV}

By mobilizing the ABV as a conceptual lens for BMI, this study also provides insights that refine the ABV in two ways (Ocasio, 201 I; Ocasio, Laamanen, \& Vaara, 20l8).
First, our study highlights the role of distributed attention (Ocasio, 201 I; Orvain, 2014) through which the reallocation of organizational resources supports the translation of an idea into concrete actions. While previous studies addressing attentional processes of innovation mainly focused on selective and engaged attention (Kim et al., 2016; Li et al., 2013), only a few studies analyzed the role of distributed attention (see Vuori \& Huy, 20 16). In line with studies demonstrating that resource allocation strategies affect innovation performance (Klingebiel \& Rammer, 20।4), we suggest that distributed attention is critical for innovation processes, explaining how new ideas are operationally concretized. In particular, our study shows that when actors are unable to switch to distributed attention, the attentional object falls into an 'attentional trap': paradoxically, an attentional object can be 'dropped' despite the amount of attention it receives. Those results challenge the established idea that attention mechanically leads to organizational moves (Shepherd et al., 2017). Instead, since organizations must constantly manage a stock of attentional objects, they might be tempted to be opportunist: they may prioritize those that require less effort to be translated into action and to set apart highly demanding objects. Those considerations invite further research on the role of distributed attention in innovation processes.

Second, we contribute to the recent refinements of the ABV model by throwing light on the attentional triggers that allow variations of attention. Previous studies have provided an understanding of the characteristics of those forms of attention (Dane, 2013; Rerup, 2009) and shown that processes of strategic and organizational change rely on a succession of attention forms (Shepherd et al., 2017). Nonetheless, these insights raise questions about the conditions that allow switching from one form of attention to another (Orvain, 20I4). Our study reveals specific triggers for BMl, which can be explained by the particularities of the organizational context. Indeed, the existence of an internal team dedicated to BMI can be compared to a situation of 'corporate entrepreneurship' (Sharma \& Chrisman, 1999) where corporate entrepreneurship teams compete with existing business activities for corporate attention (Burgelman \& Valikangas, 2005; Sakhdari, 20 I6). We highlight the conditions through which those entrepreneurial efforts, in our case by the BMI team, led to changes at the corporate level by entering the concretization phase. The triggers identified in this study (structural dissonance, realignment of repertoires and managerial action with positive feedback) account for aspects of 'attentional structures' and 'communicative channels' in the ABV model.

\section{Practical implications}

By studying BMl at Consultor, we shed light on how a consulting firm can develop a new functioning logic to run its business, overstepping novelty related to product or process 
innovation (Avadikyan et al., 20 I6). In that way, our study provides several implications for practice. First, we observe that $\mathrm{BMI}$ in established firms, in terms of strategy, develops in both deliberate and emergent ways (Mintzberg \& Waters, 1985). Thus, in their daily activities, managers should be aware of topics and cues from the environment that do not fit with their existing way of thinking and running the business. In other words, dissonances with the prevailing BM could be considered to be opportunities for BMI. Moreover, the prevailing BM, instead of impeding new BM development, could constitute a type of reference that actors can use to detect elements from the environment that do not fit with the existing structures, that is, for exploring opportunities and overstepping their path dependencies and cognitive myopia (Chesbrough \& Rosenbloom, 2002).

Second, our study suggests that to avoid 'attentional trap', that is, getting stuck at the incubation stage, firms should focus on creating triggering mechanisms rather than allocating endless amounts of time and effort. For example, firms can insist on creating organizational rituals of 'go/nogo' decisions to launch a new idea, forcing interactions with external stakeholders at early stages to obtain feedback or defining incentives for managers who proactively champion new ideas. Moreover, contrary to the previous studies that focus on top managers' role (Frankenberger \& Sauer, 2019; Govindarajan \& Trimble, 201 I), we stress that including various stakeholders is crucial for new BM development, such as internal actors (e.g. managers or employees) or customers and partners, to gather feedback.

\section{Limitations and research avenues}

We investigated BMI through a single case study: our model of the attentional process driving BMI needs further validation. More specifically, the allocation of attention may vary among firms with different characteristics and settings. In particular, we studied a consulting firm - operating in a mature sector - with a flexible structure, greater potential for generating new ideas, and immaterial resources. For instance, the NOP team could develop and drop many ideas without relying on any major investment (e.g. major purchases, and R\&D investments). Therefore, the innovation dynamic may vary over industries where reconfiguring BM implies important financial investments. Moreover, the financial health of the company may also influence the willingness to innovate and take business risks (Bromiley, 199I; Makri, Lane, \& Gomez-Mejia, 2006). Firm size may also be relevant. For instance, researchers may observe different BMI dynamics in a large company, where many levels separate operational activities from strategic decision-making and where units are more clearly separated. In particular, in large firms, top management may not be systematically part of the internal teams in charge of BMI, which could encompass actors such as middle managers. In this case, the BMI process may involve activities of 'championing' ideas (Burgelman, 1983), or 'issue-selling' (Dutton \& Ashford, 1993), to convince top management to change their strategic orientations. This would imply taking not only a time but also a space focus of BMI to track how ideas circulate within the firm until their concretization.

Moreover, our study was mainly delimited by the activities and discussions that occurred within the firm. Although we provide a rich understanding of what happened inside the NOP team, we presume that other attentional mechanisms may happen outside this scope: CEOs' and managers' cognitive repertoires are also influenced by many other aspects of their professional and personal life, such as their personal network or their previous experiences (Dane, 2013). Other analytical methods such as cognitive maps (Calori, Johnson, \& Sarnin, 1994) can complete our understanding of the attentional mechanisms that underlie BMI.

In addition, the fact that actors in the field did not mobilize the BM concept raises the question of whether the use of a BM framework (such as Osterwalder and Pigneur's Canvas) would have affected BMI. Other studies show that material and formal aspects are critical for new BM development (Demil \& Lecocq, 2015), and more broadly for strategic innovation (Fréchet \& Goy, 2017).

Consequently, our findings suggest several directions for future investigations. For instance, further studies should explore the competitive relations among attentional objects that feed BMI. Attentional objects may benefit from synergies or can interfere with one another since an organization cannot attend to all of them equally. Considering BMI to be a competitive arena of attentional objects may open a fertile ground to address the cognitive aspects of this process in more detail. In the same manner, studying how attention is allocated among various BMs in a same firm may explain how firms develop and manage a portfolio of BMs (Aversa et al., 2017 ; Sabatier et al., 20 10). The ABV thus provides a promising conceptual framework to address the complexity of managing multiple BMs (Snihur \& Tarzijan, 2018). Exploring the temporal dimension is another way to develop our attentional process of BMI. Indeed, while some attentional objects were rapidly developed, others observed slower attentional phases. For instance, future studies could investigate the role of attentional factors in accelerating or slowing BMI, such as objects' saliency (Bundy, Shropshire, \& Buchholtz, 2013). Finally, our study focused on an incremental process of BMI. Studies could also investigate radical BMI such as firms' reactions to a disruption in their environment. In this case, the challenge may not only rely on the allocation of organizational attention but also on the way in which the actors reconstruct a shared understanding of their environment and their BM. A theoretical lens such as sensemaking (Weick, 1995) could therefore be complementary to the ABV. 


\section{References}

Arend, R. J. (2013). The business model: Present and future - Beyond a skeumorph. Strategic Organization, II(4), 390-402. doi: 10.1 | 77/| 476127013499636

Atkinson, P. \& Hammersley, M. (1994). Ethnography and participant observation. In N. K. Denzin \& Y. S. Lincoln (Eds.), Handbook of qualitative research (pp. 248-260). Thousand Oaks, CA: Sage.

Avadikyan, A., Lhuillery, S. \& Negassi, S. (2016). Technological innovation, organizational change, and product-related services. M@n@gement, 19(4), 277-304. doi: 10.3917/mana.194.0277

Aversa, P., Haefliger, S. \& Reza, D. G. (2017). Building a winning business model Portfolio. MIT Sloan Management Review, 58(4), 49-54. Retrieved from https://openaccess.city.ac.uk/id/eprint/I7978

Aversa, P., Haefliger, S., Rossi, A. \& Baden-Fuller, C. (2015). From business model to business modelling: Modularity and manipulation. In C. BadenFuller \& V. Mangematin (Eds.), Business models and modelling, advances in strategic management (vol. 33, pp. I5 I-185). United Kingdom: Emerald Group.

Baden-Fuller, C. \& Mangematin, V. (20|5). Business models and modelling business models. In C. Baden-Fuller \& V. Mangematin (Eds.), Business models and modelling (pp. xi-xxii). United Kingdom: Emerald Group.

Baden-Fuller, C. \& Morgan, M. S. (2010). Business models as models. Long Range Planning, 43(2-3), I56- I7।. doi: I0. I 0 I 6/j.Irp.20 I0.02.005

Bem, D. J. (1972). Self-perception theory. Advances in Experimental Psychology, New York, NY: Academic Press, 6(I), I-62.

Berends, H., Smits, A., Reymen, I. \& Podoynitsyna, K. (20I6). Learning while (re)configuring: Business model innovation processes in established firms. Strategic Organization, 14(3), |81-219. doi: 10.1 |77/|476 | 270 | 6632758

Bettis, R. A. \& Prahalad, C. K. ( 1995). The dominant logic: Retrospective and extension. Strategic Management Journal, I6(I), 5-14. doi: 10.1002/ smj.4250160104

Bjorkdahl, J. (2009). Technology cross-fertilization and the business model: The case of integrating ICTs in mechanical engineering products. Research Policy, 38(9), | 468-| 477. doi: I0.10 I 6/j.respol.2009.07.006

Bjorkdahl, J. \& Holmén, M. (20।3). Editorial: Business model innovation The challenges ahead. International Journal of Product Development, 18(3/4), 213-225.

Bohnsack, R, Pinkse, J. \& Kolk, A. (2014). Business models for sustainable technologies: Exploring business model evolution in the case of electric vehicles. Research Policy, 43(2), 284-300. doi: 10.1016/j.respol.2013.10.014

Bojovic, N., Genet, C. \& Sabatier,V. (20।8). Learning, signaling, and convincing:The role of experimentation in the business modeling process. Long Range Planning, 5 I ( ), I4 I-157. doi: 10.1016/j.Irp.2017.09.00 I

Bourgoin, A., Bencherki, N. \& Faraj, S. (2019). "And Who Are You?": A performative perspective on authority in organizations. Academy of Management Journal. doi: 10.5465/amj.2017.1335

Bourgoin, A. \& Harvey, J.-F. (20 | 8). Professional image under threat: Dealing with learning-credibility tension. Human Relations, 7/ (|2), |6 | |-1639. doi: 10.1 177/00187267|8756168

Bromiley, P. (1991). Testing a causal model of corporate risk taking and performance. Academy of Management Journal, 34(I), 37-59. doi: |0.5465/25630|

Bundy, J., Shropshire, C. \& Buchholtz, A. K. (2013). Strategic cognition and issue salience: toward an explanation of firm responsiveness to stakeholder concerns. Academy of Management Review, 38(3), 352-376. doi: 10.5465/amr.201 I.0179

Burgelman, R. A. (1983). Corporate entrepreneurship and strategic management: Insights from a process study. Management Science, 29(12), | 349-|364. doi: | 0.1287/mnsc.29.12.1349
Burgelman, R. A. \& Valikangas, L. (2005). Managing internal corporate venturing cycles. MIT Sloan Management Review, 46(4), 26-38.

Calori, R. (2002). Organizational development and the ontology of creative dialectical evolution. Organization, 9(I), 127-150. doi: 10.1177/ | $35050840200900 \mid 352$

Calori, R., Johnson, G. \& Sarnin, P. (1994). CEOs' cognitive maps and the scope of the organization. Strategic Management Journal, 15(6), 437-457. doi: 10.1002/smj.4250150603

Casadesus-Masanell, R. \& Ricart, J. E. (2010). From strategy to business models and onto tactics. Long Range Planning, 43(2-3), 195-215. doi: 10.10 16/j.Irp.2010.01.004

Casadesus-Masanell, R. \& Zhu, F. (2013). Business model innovation and competitive imitation: The case of sponsor-based business models. Strategic Management Journal, 34(4), 464-482. doi: I 0. I002/smj.2022

Chesbrough, H. (2010). Business model innovation: Opportunities and barriers, Long Range Planning, 43(2-3), 354-363. doi: I 0. I O I 6/j.Irp.2009.07.0 I0

Chesbrough, H. \& Rosenbloom, R. S. (2002). The role of the business model in capturing value from innovation. Industrial and Corporate Change, I / (3), 529-555. doi: 10.1093/icc/ I I.3.529

Chesbrough, H. \& Schwartz, K. (2007). Innovating business models with co-development partnerships. Research-Technology Management, 50(I), 55-59. doi: I0. I080/08956308.2007.I | 657419

Cortimiglia, M. N., Ghezzi, A. \& Frank, A. G. (2015). Business model innovation and strategy making nexus: Evidence from a cross-industry mixed-methods study. R\&D Management, 46(3), 4 I4-432. doi: I0. I I I I/ radm. 12113

Cyert, R. M. \& March, J. G. (1963). A behavioral theory of the firm (vol. 2). In J. B. Miner, Organizational behavior 2: Essential theories of process and structure (ch. 4, pp. 60-77). New York, NY: M. E. Sharpe.

D'Aveni, R. A. \& MacMillan, I. C. (1990). Crisis and the content of managerial communications. Administrative Science Quarterly, 35(4), 634-657. doi: 10.2307/23935 I 2

Dahlander, L. \& O'Mahony, S. (2016). One foot in, one foot out: how does individuals' external search breadth affect innovation outcomes? Strategic Management Journal, 37(2), 280-302. doi: I0. I002/smj.2342

Dane, E. (20/3). Things seen and unseen: Investigating experience-based ualities of attention in a dynamic work setting. Organization Studies, 34(I), 45-78. doi: I0.1 | 77/01708406 I 2464752

Demil, B. \& Lecocq, X. (20।0). Business model evolution: In search of dynamic consistency. Long Range Planning, 43(2-3), 227-246. doi: 10. 10 | 6/j.Irp.2010.02.004

Demil, B. \& Lecocq, X. (2015). Crafting an innovative business model in an established company: The role of artifacts. In C. Baden-Fuller \& V. Mangematin (Eds.), Business models and modelling (pp. 3I-58). United Kingdom: Emerald Group.

Demil, B., Lecocq, X., Ricart, J. E. \& Zott, C. (20I5). Introduction to the SEJ Special Issue on business models: Business models within the domain of strategic entrepreneurship. Strategic Entrepreneurship Journal, 9( I), I- I I. doi: 10.1002/sej. I 194

Doganova, L. \& Eyquem-Renault, M. (2009). What do business models do? Research Policy, 38( I0), I559-1570. doi: I0. I0 I 6/j.respol.2009.08.002

Dutton, J. E. (1997). Strategic agenda building in organizations. In Z. Shapira (Ed.), Organizational decision making (pp. 8I-105). Cambridge, MA: Cambridge University Press.

Dutton, J. E. \& Ashford, S. J. (1993). Selling issues to top management. Academy of Management Review, 18(3), 397-428. doi: 10.5465/ amr.1993.9309035। 45

Eisenhardt, K. M. \& Graebner, M. E. (2007). Theory building from cases: Opportunities and challenges. The Academy of Management Journal, 50(I), 25-32. doi: I0.5465/amj.2007.24160888 
European Commission. (2014). The need for innovations in business models. $D G$ research and innovation.

Festinger, L. (1957). A theory of dissonance cognitive. Row: Evanston.

Foss, N. J. \& Saebi, T. (20I5). Business models and business model innovation: Bringing organization into the discussion. In N. J. Foss \& T. Saebi (Eds.), Business model innovation (pp. I-23). Oxford: Oxford University Press.

Foss, N. J. \& Saebi, T. (2017). Fifteen years of research on business model innovation: How far have we come, and where should we go? Journal of Management, 43(I), 200-227. doi: I 0.1 I77/0 | 492063 | 6675927

Frankenberger, K. \& Sauer, R. (2019). Cognitive antecedents of business models: Exploring the link between attention and business model design over time. Long Range Planning, 52(3), 283-304. doi: 10.1016/j. Irp.20|8.05.00 |

Fréchet, M. \& Goy, H. (2017). Does strategy formalization foster innovation? Evidence from a French sample of small to medium-sized enterprises.M@n@gement,20(3),266-286.doi: 10.3917/ mana.203.0266

Gavetti, G. \& Ocasio, W. (20I5). Cognition \& strategy. United Kingdom: Emerald Group.

Giesen, E., Berman, S. J., Bell, R. \& Blitz, A. (2007). Three ways to successfully innovate your business model. Strategy \& Leadership, 35(6), 27-33. doi: | 0.1 | 108/108785707/ 0833732

Gioia, D. A., Corley, K. G. \& Hamilton, A. L. (20।3). Seeking qualitative rigor in inductive research notes on the Gioia methodology. Organizational Research Methods, I 6 ( ), I5-3 I. doi: I 0. I I77/ | 094428 I I2452 I5 |

Gioia, D. A., Price, K. N., Hamilton, A. L., \& Thomas, J. B. (20 I 0). Forging an identity: An insider-outsider study of processes involved in the formation of organizational identity. Administrative Science Quarterly, 55(I), |-46. doi: I0.2 | 89/asqu.20 I0.55. I. |

Glaser, B. G. \& Strauss, A. L. (2017). Discovery of grounded theory: Strategies for qualitative research. London: Routledge.

Govindarajan,V. \& Trimble, C. (20I I). The CEO's role in business model reinvention. Harvard Business Review, 89( I-2), I08-I I 4. PMID: 21370808.

Greve, H. R. (2008). A behavioral theory of firm growth: Sequential attention to size and performance goals. Academy of Management Journal, 5I (3), 476-494. doi: I0.5465/amj.2008.32625975

Hacklin, F., Bjorkdahl, J. \& Wallin, M.W. (20 I 8). Strategies for business model innovation: How firms reel in migrating value. Long Range Planning, 5I ( I), 82-I I 0. doi: I0.10 I6/j.Irp.2017.06.009

Hansen, M.T., \& Haas, M. R. (200 I). Competing for attention in knowledge markets: electronic document dissemination in a management consulting company. Administrative Science Quarterly, 46( I), I-28. doi: I0.2307/ 2667I 23

IBM Corporation. (2008). The Enterprise of the Future: IBM Global CEO Study 2008, IBM Corporation.

Joseph, J. \& Ocasio,W. (20I2). Architecture, attention, and adaptation in the multibusiness firm: General electric from 195I to 200I. Strategic Management Journal, 33(6), 633-660. doi: I0. I002/smj. $197 \mid$

Khanagh, S., Volberda, H. \& Oshri, I. (20I4). Business model renewal and ambidexterity: Structural alteration and strategy formation process during transition to a Cloud business model. R\&D Management, 44(3), 322-340. doi: 10.1 I I //radm. 12070

Kim, B., Kim, E. \& Foss, N. J. (20।6). Balancing absorptive capacity and inbound open innovation for sustained innovative performance: An attention-based view. European Management Journal, 34(I), 80-90. doi: I0. I0 |6/j.emj.2015. I0.002

Kim, S. K. \& Min, S. (2015). Business model innovation performance: When does adding a new business model benefit an incumbent? Strategic Entrepreneurship Journal, 9(I), 34-57. doi: 10.1002/sej.II93
Klingebiel, R. \& Rammer, C. (20I4). Resource allocation strategy for innovation portfolio management. Strategic Management Journal, 35(2), 246-268. doi: 10.1002/smj.2107

Langley, A. (1999). Strategies for theorizing strategies from process data. Academy of Management Review, 24(4), 69I-7I0. doi: 10.5465/ amr.1999.2553248

Laudien, S. M. \& Daxböck, B. (20 I6). Path dependence as a barrier to business model change in manufacturing firms: Insights from a multiple-case study. Journal of Business Economics, 86(6), 61 I-645. doi: 10.1007/ sl I573-015-0793-I

Laszczuk, A. \& Garreau, L. (2018). The sibylline research diary. Finance Contrôle Stratégie, 2 I (3), I-26. doi: 10.4000/fcs.35 I9

Lecocq, X., Demil, B. \& Ventura, J. (20I0). Business models as a research program in strategic management:An appraisal based on Lakatos.M@n@ gement, 13(4), 214-225. doi: 10.39/7/mana. I34.0214

Lehoux, P., Daudelin, G., Williams-Jones, B., Denis, J. L., et al. (2014). How do business model and health technology design influence each other? Insights from a longitudinal case study of three academic spin-offs. Research Policy, 43(6), I025-I038. doi: I 0. I 0 | 6/j.respol.20 I 4.02.00 I

Li, Q., Maggitti, P. G., Smith, K. G., Tesluk, P. E., et al. (20 I 3). Top management attention to innovation:The role of search selection and intensity in new product introductions. Academy of Management Journal, 56(3), 893-916. doi: $10.5465 /$ amj.20 10.0844

Lindgardt, Z., Reeves, M., Stalk, G. \& Deimler, M. S. (2009). Business model innovation. When the game gets tough, change the game. Boston, MA: The Boston Consulting Group.

Makri, M., Lane, P. J. \& Gomez-Mejia, L. R. (2006). CEO incentives, innovation, and performance in technology-intensive firms: A reconciliation of outcome and behavior-based incentive schemes. Strategic Management Journal, 27(I I), I057-1080. doi: I0. I002/smj.560

Mangematin, V., Ravarini, A. M. \& Sharkey Scott, P. (2017). Practitioner insights on business models and future directions. Journal of Business Strategy, 38(2), 3-5. doi: 10.1 108/JBS-10-2016-0 130

Markides, C.\& Charitou, C. D. (2004). Competing with dual business models: A contingency approach. Academy of Management Executive, 18(3), I- | 6. doi: | 0.5465/ame.2004. I 4776 | 64

Markides, C. C. (20I3). Business model innovation:What can the ambidexterity literature teach US? Academy of Management Perspectives, 27(4), 313-323. doi: 10.5465/amp.2012.0172

Martins, L. L., Rindova, V. P. \& Greenbaum, B. E. (20I5). Unlocking the hidden value of concepts: A cognitive approach to business model innovation. Strategic Entrepreneurship Journal, 9(1), 99-117. doi: 10.1002/sej. I191

Massa, L., \& Tucci, C. L. (20।4). Business model innovation. In M. Dodgson, D. M. Gann \& N. Phillips (Eds.), The Oxford handbook of innovation management (pp. 420-44I). Oxford: Oxford University Press.

Massa, L., Tucci, C. L. \& Afuah, A. (20 17). A critical assessment of business model research. The Academy of Management Annals, I I (2), 73-104. doi: | 0.5465/annals.20|4.0072

Maucuer, R. \& Renaud, A. (2019). Business model research: A bibliometric analysis of origins and trends. M@N@gement, 22(2), 176-215. doi: 10.3917/mana.222.0176

McMullen, J. S., Shepherd, D. A. \& Patzelt, H. (2009). Managerial (in)attention to competitive threats. Journal of Management Studies, 46(2), |57-|8|. doi: | 0. I | | |/j. | 467-6486.2008.00799.x

Mezger, F. (20।4). Toward a capability-based conceptualization of business model innovation: Insights from an explorative study. R\&D Management, 44(5), 429-449. doi: 10.1 I I I/radm. 12076

Mintzberg, H. \& Waters, J. A. (1985). Of strategies, deliberate and emergent. Strategic ManagementJournal, 6(3),257-272. doi: I 0. I 002/smj.4250060306 
Moingeon, B. \& Lehmann-Ortega, L. (20 I0). Creation and implementation of a new business model: A disarming case study. M@n@gement, 13(4), 266-297. doi: I0.39|7/mana. 134.0266

Morris, M. Schindehutte, M. \& Allen, J. (2005). The entrepreneur's business model:Toward a unified perspective. Journal of Business Research, 58(6), 726-735. doi: | 0.10 | 6/j.jbusres.2003.1 I.001

Naveh, E. \& Erez, M. (2004). Innovation and attention to detail in the quality improvement paradigm. Management Science, 50(I I), I576-1586. doi: I $0.1287 /$ mnsc. 1040.0272

Nigam, A. \& Ocasio,W. (20 I 0). Event attention, environmental sensemaking, and change in institutional logics: An inductive analysis of the effects of public attention to Clinton's health care reform initiative. Organization Science, 2 I (4), 823-84I. doi: 10. I 287/orsc. 1090.0490

Ocasio,W. (1997). Towards an attention-based view of the firm. Strategic Management Journal, 18, 187-206. doi: 10.1002/(SICl) 1097-0266 ( 199707$)$ | 8: | +\%3C 187::AID-SMJ936\%3E3.3.CO;2-B

Ocasio, W. (201 I). Attention to attention. Organization Science, 22(5), 1286-|296. doi: | 0.1287/orsc. I 100.0602

Ocasio, W., Laamanen, T. \& Vaara, E. (20|8). Communication and attention dynamics: An attention-based view of strategic change. Strategic Management Journal, 39(I), I55-167. doi: I0. I002/smj.2702

Orvain, J. (20|4). Organizational qui-vive: An intermediate approach to structuring the link between attention and action.M@n@gement, 17(5), 346-370. doi: I0.39|7/mana. 175.0346

Osiyevskyy, O.\& Dewald, J. (20 I5). Explorative versus exploitative business model change:The cognitive antecedents of firm-level responses to disruptive innovation. Strategic Entrepreneurship Journal, 9(I), 58-78. doi: 10.1002/sej. I 192

Osterwalder, A. \& Pigneur,Y. (20 I 0). Business model generation: A handbook for visionaries, game changers, and challengers. Hebaken, NJ: John Wiley \& Sons.

Piezunka, H. \& Dahlander, L. (20I5). Distant search, narrow attention: How crowding alters organizations' filtering of suggestions in crowdsourcing. Academy of Management Journal, 58(3), 856-880. doi: I 0.5465/ amj.2012.0458

Rerup, C. (2009). Attentional triangulation: Learning from unexpected rare crises. Organization Science, 20(5),876-893. doi: I 0. I 287/orsc. 1090.0467

Rhee, L. \& Leonardi, P. M. (2018). Which pathway to good ideas? An attention-based view of innovation in social networks. Strategic Management Journal, 39(4), I I 88-1215. doi: 10.1002/smj.2755

Rumble, R. \& Mangematin, V. (2015). Business model implementation:The antecedents of multi-sidedness. In C. Baden-Fuller \& V. Mangematin (Eds.), Business models and modelling, advances in strategic management (vol. 33, pp. 97-131). United Kingdom: Emerald Group.

Sabatier, V., Mangematin, V. \& Rousselle, T. (20 I0). From recipe to dinner: Business model portfolios in the European biopharmaceutical industry. Long Range Planning, 43(2-3): 43 I-447. doi: I 0. I 0 I 6/.Irp.20 I 0.02.00 I

Saebi, T., Lien, L. \& Foss, N. J. (2017). What drives business model adaptation? The impact of opportunities, threats and strategic orientation. Long Range Planning, 50(5), 567-58 I doi: I 0. I 0 I 6/j.Irp.20 I 6.06.006

Sakhdari, K. (2016). Corporate entrepreneurship: A review and future research agenda. Technology Innovation Management Review, 6(8), 5-18. doi: 10.222 I5/timreview/ 007

Santos, J. F. P. D., Spector, B., \& Van Der Heyden, L. (20I5). Toward a theory of business model change. In N. J. Foss \& T. Saebi (Eds.), Business model innovation (pp. 43-63). Oxford: Oxford University Press.

Schneckenberg, D., Velamuri,V. K., Comberg, C. \& Spieth, P. (2017). Business model innovation and decision making: Uncovering mechanisms for coping with uncertainty. R\&D Management, 47(3), 404-419. doi: | 0.1 | | |/radm. 12205
Schneider, S. \& Spieth, P. (20/3). Business model innovation: Towards an integrated future research agenda. International Journal of Innovation Management, I 7(I), I34000 I - I-34.doi: I0.I I42/SI3639 I96 I34000 IX

Sharma, P. \& Chrisman, J. J. (1999). Toward a reconciliation of the definitional issues in the field of corporate entrepreneurship. Entrepreneurship Theory and Practice, 23(3), II-27. doi: 10.1177/ 104225879902300302

Shepherd, D. A., McMullen, J. S. \& Ocasio,W. (20 I7). Is that an opportunity? An attention model of top managers' opportunity beliefs for strategic action. Strategic Management Journal, 38(3), 626-644. doi: I0.1002/ smj.2499

Simon, H. A. (1947). Administrative behavior. Chicago, IL: Macmillan.

Smith, W. K., Binns, A. \& Tushman, M. L. (20।0). Complex business models: Managing strategic paradoxes simultaneously. Long Range Planning, 43(2-3), 448-46I. doi: 10.1002/smj.2499

Snihur, Y. \& Tarzijan, J. (20/8). Managing complexity in a multi-businessmodel organization. Long Range Planning, 5I (1), 50-63. doi: 10.1016/j. Irp.2017.06.010

Snihur,Y. \& Wiklund, J. (2019). Searching for innovation: Product, process, and business model innovations and search behavior in established firms. Long Range Planning, 52(3), 305-325. doi: I 0. I 0 | 6/j.Irp.20 I 8.05.003

Sosna, M.,Trevinyo-Rodriguez, R. N. \& Velamuri, S. R. (20 I0). Business model innovation through trial-and-error learning. Long Range Planning, 43(23), 383-407. doi: 10.101 6/j.Irp.20 10.02.003

Stanko, T. L. \& Beckman, C. M. (20I5). Watching you watching me: Boundary control and capturing attention in the context of ubiquitous technology use. Academy of Management Journal, 58(3), 7I2-738. doi: 10.5465/ amj.20 I2.09। I

Surroca, J., Prior, D. \& TribóGiné, J. A. (2016). Using panel data DEA to measure CEOs' focus of attention: An application to the study of cognitive group membership and performance. Strategic Management Journal, 37(2), 370-388. doi: 10.1002/smj.2350

Teece, D. J. (20 I0). Business models, business strategy and innovation. Long Range Planning, 43(2-3), 172-194. doi: I0. I 0 l 6/j.Irp.2009.07.003

Tripsas, M. \& Gavetti, G. (2000). Capabilities, cognition, and inertia: Evidence from digital imaging. Strategic Management Journal, 21(10/1 I),

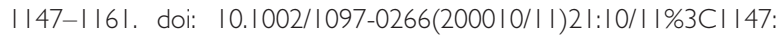
AID-SMJ I28\%3E3.0.CO;2-R

Van De Ven, A. H. (1992). Suggestions for studying strategy process: A research note. Strategic Management Journal, 13, 169-191. doi: I0.1002/ smi.4250131013

Velu, C. \& Stiles, P. (20।3). Managing decision-making and cannibalization for parallel business models. Long Range Planning, 46(6), 443-458. doi: I0.1016/j.Irp.2013.08.003

Vuori, T. O. \& Huy, Q. N. (2016). Distributed attention and shared emotions in the innovation process. Administrative Science Quarterly, 6I (I), 9-51. doi: | 0.1 1 777/000 | 83921560695 |

Walrave, B., Romme, A. G. L., van Oorschot, K. E. \& Langerak, F. (2017). Managerial attention to exploitation versus exploration: Toward a dynamic perspective on ambidexterity. Industrial and Corporate Change, 26(6), I | 45-| | 60. doi: 10.1093/icc/dt×0 I 5

Weick, K. E. (1995). Sensemaking in organizations. Thousand Oaks, CA: Sage.

Weick, K. E. \& Sutcliffe, K. M. (2006). Mindfulness and the quality of organizational attention. Organization Science, 17(4), 5|4-524. doi: 10.1287/ orsc. 1060.0196

Weick, K. E. \& Sutcliffe, K. M. (2008). Information overload revisited. In G. P. Hodgkinson \&W. H. Starbuck (Eds.), The Oxford handbook of organizational decision making (pp. 56-75). Oxford: Oxford University Press. 
Winterhalter, S., Weiblen, T., Wecht, C. H. \& Gassmann, O. (2017). Business model innovation processes in large corporations: insights from BASF. Journal of Business Strategy, 38(2), 62-75. doi: 10.1 108/ JBS- I0-2016-01 I6

Yadav, M. S., Prabhu, J. C. \& Chandy, R. K. (2007). Managing the future: CEO attention and innovation outcomes. Journal of Marketing, 7 I (4), 84-I0I. doi: | 0.1509/jmkg.7|.4.084
Yin, R. K. (20 I3). Case study research: Design and methods. Thousand Oaks, CA: Sage.

Zott, C.\& Amit, R. (2007). Business model design and the performance of entrepreneurial firms. Organization Science, 18(2), I8I-199. doi: 10.1287/orsc. I060.0232

Zott, C. \& Amit, R. (20 I0). Business model design: An activity system perspective. Long Range Planning, 43(2-3), 21 6-226. doi: I 0. I 1 / 6/j.Irp.2009.07.004 
Appendix I. Data inventory I-recorded events

\begin{tabular}{|c|c|c|c|c|}
\hline$\#$ & Date & Event type & Attendees & Length in minutes \\
\hline I & 20 February 2014 & Internal meeting & 3 & 28 \\
\hline 2 & 08 April 2014 & Internal meeting & 3 & 87 \\
\hline 3 & 25 April 2014 & Internal meeting & 3 & 81 \\
\hline 4 & 16 May 2014 & Internal meeting & 3 & 83 \\
\hline 5 & 29 June 2014 & Internal meeting & 3 & 279 \\
\hline 6 & 10 October 2014 & Internal meeting & 3 & 179 \\
\hline 7 & 06 November 2014 & Internal meeting & 3 & 60 \\
\hline 8 & 06 January 2015 & Discussion about the NOP & 2 & 115 \\
\hline 9 & 26 January 2015 & Internal meeting & 3 & 201 \\
\hline 10 & 06 February 2015 & Phone conversation & 3 & 16 \\
\hline $\mid 1$ & 24 February 2015 & Internal meeting & 3 & 221 \\
\hline 12 & 04 March 2015 & Workshop & 2 & 86 \\
\hline 13 & I I March 2015 & Business lunch & 4 & 96 \\
\hline 14 & 12 March 2015 & Workshop & 2 & 93 \\
\hline 15 & 18 March 2015 & Discussion about the NOP & 3 & 24 \\
\hline 16 & 25 March 2015 & Workshop & 2 & 63 \\
\hline 17 & 03 April 2015 & Internal meeting & 3 & 59 \\
\hline 18 & 14 April 2015 & Conference & 30 & 110 \\
\hline 19 & 12 June 2015 & Discussion about the NOP & 2 & 85 \\
\hline 20 & 16 June 2015 & Workshop & 2 & 73 \\
\hline 21 & 19 June 2015 & Internal meeting & 3 & 53 \\
\hline 22 & 17 July 2015 & Workshop & 2 & 115 \\
\hline 23 & 22 July 2015 & Workshop & 3 & 51 \\
\hline 24 & 07 October 2015 & Internal meeting & 3 & 163 \\
\hline 25 & 16 October 2015 & Internal meeting & 5 & 122 \\
\hline 26 & 30 October 2015 & Workshop & 4 & 76 \\
\hline 27 & 13 November 2015 & Business lunch & 2 & 22 \\
\hline 28 & 19 November 2015 & Workshop & 4 & 51 \\
\hline 29 & 27 November 2015 & Workshop & 2 & 52 \\
\hline 30 & 08 December 2015 & Business lunch & 5 & 55 \\
\hline 31 & 25 January 2016 & Meeting & 5 & 63 \\
\hline 32 & | | February 2016 & Meeting & 5 & 122 \\
\hline 33 & 29 February 2016 & Workshop & 3 & 122 \\
\hline 34 & 07 March 2016 & Workshop & 3 & 118 \\
\hline 35 & 18 April 2016 & Phone conversation & 2 & 53 \\
\hline 36 & 02 May 2016 & Internal meeting & 4 & 103 \\
\hline 37 & 30 May 2016 & Internal meeting & 18 & 110 \\
\hline 38 & 2 IJuly 2016 & Internal meeting & 5 & 230 \\
\hline 39 & 08 September 2016 & Workshop & 4 & 72 \\
\hline 40 & 26 September 2016 & Workshop & 3 & 61 \\
\hline 41 & 28 September 2016 & Phone conversation & 3 & 3 \\
\hline 42 & 18 October 2016 & Internal meeting & 5 & 66 \\
\hline 43 & 07 November 2016 & Internal meeting & 5 & 45 \\
\hline 44 & I 8 November 2016 & Discussion about the NOP & 2 & 35 \\
\hline 45 & 09 December 2016 & Internal meeting & 52 & 70 \\
\hline
\end{tabular}


Appendix 2. Data inventory II - interviews

\begin{tabular}{lllc}
\hline$\#$ & Date & Function & Length in minutes \\
\hline 1 & 7 July 2015 & Partner I & 72 \\
2 & 22 July 2015 & Partner 2 & 57 \\
3 & 7 February 2016 & Senior manager consultant & 94 \\
4 & 24 February 2016 & Partner 1 & 63 \\
5 & 14 March 2016 & Partner 2 & 103 \\
6 & 17 March 2016 & Consultant & 78 \\
7 & 26 October 2016 & Partner 1 & 55 \\
8 & 17 November 2016 & Partner 2 & 51 \\
\hline
\end{tabular}

Appendix 3. Actors involved in the NOP

\begin{tabular}{ll}
\hline Name & Position \\
\hline Bernard & Consultor's CEO \\
Laura & Consultor's director \\
Patel & ITPartner's CEO \\
Louise & A Consultor's consultant \\
Jacques & A Consultor's consultant \\
Nicolas & A Consultor's customer \\
\hline
\end{tabular}

CEO, chief executive officer; NOP, New Offer Project. 